\title{
COUPLED INVERSE MODELING OF A CONTROLLED IRRIGATION EXPERIMENT USING MULTIPLE HYDRO-GEOPHYSICAL DATA
}

\section{This is the author's manuscript}

Original Citation:

\section{Availability:}

This version is available http://hdl.handle.net/2318/1509432

since 2015-12-16T14:51:09Z

Published version:

DOI:10.1016/j.advwatres.2015.03.008

Terms of use:

Open Access

Anyone can freely access the full text of works made available as "Open Access". Works made available under a Creative Commons license can be used according to the terms and conditions of said license. Use of all other works requires consent of the right holder (author or publisher) if not exempted from copyright protection by the applicable law. 


\section{Accepted Manuscript}

Coupled inverse modeling of a controlled irrigation experiment using multiple hydro-geophysical data

Matteo Rossi, Gabriele Manoli, Damiano Pasetto, Rita Deiana, Stefano Ferraris, Claudio Strobbia, Mario Putti, Giorgio Cassiani

PII: S0309-1708(15)00063-9

DOI: http://dx.doi.org/10.1016/j.advwatres.2015.03.008

Reference: ADWR 2355

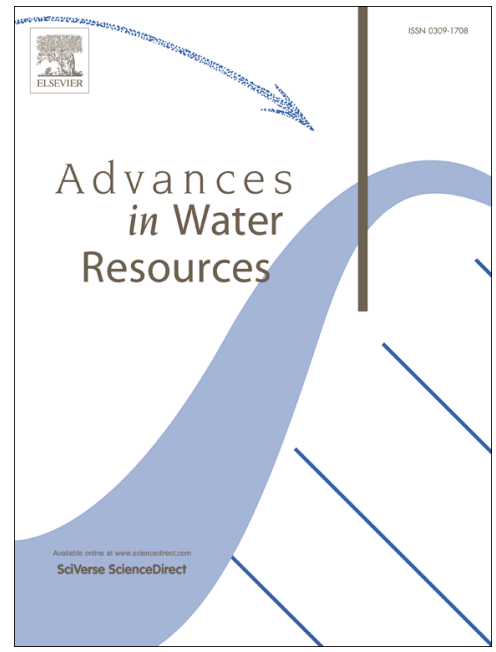

To appear in:

Advances in Water Resources

Received Date:

29 July 2014

Revised Date:

24 March 2015

Accepted Date:

25 March 2015

Please cite this article as: Rossi, M., Manoli, G., Pasetto, D., Deiana, R., Ferraris, S., Strobbia, C., Putti, M., Cassiani, G., Coupled inverse modeling of a controlled irrigation experiment using multiple hydro-geophysical data, Advances in Water Resources (2015), doi: http://dx.doi.org/10.1016/j.advwatres.2015.03.008

This is a PDF file of an unedited manuscript that has been accepted for publication. As a service to our customers we are providing this early version of the manuscript. The manuscript will undergo copyediting, typesetting, and review of the resulting proof before it is published in its final form. Please note that during the production process errors may be discovered which could affect the content, and all legal disclaimers that apply to the journal pertain. 
1 COUPLED INVERSE MODELING OF A CONTROLLED IRRIGATION EXPERIMENT USING MULTIPLE HYDRO-GEOPHYSICAL DATA

3

4 MatteoRossi $^{1}$, Gabriele Manoli ${ }^{2}$, Damiano Pasetto ${ }^{3}$,Rita Deiana ${ }^{4}$, Stefano Ferraris ${ }^{5}$, Claudio Strobbia ${ }^{6}$, Mario Putti ${ }^{3}$ and Giorgio Cassiani ${ }^{1}$

6

$7 \quad{ }^{1}$ Department of Geosciences, University of Padova, Via Gradenigo 6, 35131 Padova, Italy

82 Nicholas School of the Environment, Division of Earth and Ocean Sciences, Duke University,

9 Durham, North Carolina 27708, USA ${ }^{3}$ Department of Mathematics, University of Padova, Via

10 Trieste 63, 35121 Padova, Italy

$11{ }^{4}$ Department of Cultural Heritage, University of Padova, Piazza Capitaniato 7, 35139 Padova, Italy.

$12{ }^{5}$ Department of Agricultural, Forestry and Environmental Economics and Engineering, University

13 of Torino, Via Leonardo da Vinci 44, 10095 Grugliasco, Torino, Italy

$14{ }^{6}$ Total SA, Pau, France

15

March 25, 2015

17

18

19

20

21

24 KEYPOINT: Comparison of hydro-geophysical inversion approaches applied to a 25 surface irrigation experiment. 


\section{ABSTRACT}

27 Geophysical surveys can provide useful, albeit indirect, information on vadose 28 zone processes. However, the ability to provide a quantitative description of the 29 subsurface hydrological phenomena requires to fully integrate geophysical data 30 into hydrological modeling. Here, we describe a controlled infiltration experiment 31 that was monitored using both electrical resistivity tomography (ERT) and 32 ground-penetrating radar (GPR). The experimental site has a simple, well33 characterized subsoil structure: the vadose zone is composed of aeolic sand with 34 largely homogeneous and isotropic properties. In order to estimate the unknown soil hydraulic conductivity, we apply a data assimilation technique based on a sequential importance resampling (SIR) approach. The SIR approach allows a

37 simple assimilation of either or both geophysical datasets taking into account the 38 associated measurement uncertainties. We demonstrate that, compared to a 39 simpler, uncoupled hydro-geophysical approach, the coupled data assimilation process provides a more reliable parameter estimation and better reproduces the

41 evolution of the infiltrating water plume. The coupled procedure is indeed much 42 superior to the uncoupled approach that suffers from the artifacts of the 43 geophysical inversion step and produces severe mass balance errors. The 44 combined assimilation of GPR and ERT data is then investigated, highlighting 45 strengths and weaknesses of the two datasets. In the case at hand GPR energy 46 propagates in form of a guided wave that, over time, shows different energy 47 distribution between propagation modes as a consequence of the evolving 48 thickness of the wet layer. We found that the GPR inversion procedure may 
54

produce estimates on the depth of the infiltrating front that are not as informative as the ERT dataset.

KEYWORDS: hydro-geophysical inversion, electrical resistivity tomography, ground-penetrating radar, infiltration, vadose zone.

\section{INTRODUCTION}

Hydrological research increasingly requires detailed information to feed datahungry numerical models. For this reason, geophysical data are increasingly called into play to fill the lack of spatial and sometimes temporal resolution of traditional hydrological data. This is particularly true for the vadose zone, where the difficulties for obtaining direct measurements, the general lack of knowledge and the uncertainty on the soil parameters and their spatial heterogeneity often lead to develop numerical models that cannot reproduce the behavior of the real systems, unless they are strongly constrained by multiple, extensive and complementary data.

The vadose/unsaturated zone is home to a number of complex key processes that control the mass and energy exchanges in the subsurface (soil water migration) and between the subsurface and the atmosphere (rain infiltration, soil evaporation and plant transpiration). The understanding of vadose zone fluiddynamics is key to the comprehension of a large number of hydrologicallycontrolled environmental problems, with strong implications in water resources management and subsurface contaminant hydrology. Unsaturated processes are also key factors in a number of important issues, such as the availability of water 
73 for agriculture, slope stability, and floods. The dependence of the hydro-

74 geophysical response on changes in soil moisture content is the key mechanism

75 that allows the monitoring of the vadose zone in time-lapse mode via non-invasive

76 techniques. The use of these techniques can provide high-resolution images of

77 hydro-geological structures in the shallow and deep vadose zones and, in some

78 cases, a detailed assessment of dynamical processes in the subsurface.

79 The estimation of the time and space variations of water content using non-

80 invasive methodologies has been the focus of intensive research over the past

81 three decades. Among the numerous techniques developed in literature for such a

82 goal, such as electromagnetic induction, off-ground ground-penetrating radar,

83 surface nuclear magnetic resonance, in this work we consider electrical resistivity

84 tomography (ERT) and ground-penetrating radar (GPR). These techniques

85 measure the electrical resistivity $\rho(\Omega \mathrm{m})$ and the relative dielectric permittivity $\varepsilon_{r}$

$86(-)$ of the porous media, respectively. For both methods the determination of soil

87 water content is based upon existing relationships that link water content to the

88 geophysical quantities measured (e.g., Archie, 1942; Topp et al., 1980; Roth et al.,

89 1990; Brovelli and Cassiani, 2008, 2011).

90 When used to study hydrological dynamics, GPR surveys are often performed to

91 detect changes in soil moisture content via the variation of dielectric permittivity,

92 generally measured from GPR travel times in a variety of configurations (e.g.,

93 Huisman et al., 2003; Cassiani et al., 2006; Cassiani et al., 2008), such as borehole-

94 to-borehole (e.g., Rucker and Ferré, 2004a, 2004b; Rossi et al., 2012) or borehole-

95 to-surface (e.g., Vignoli et al., 2012). However, the most common setup uses GPR

96 antennas from the the ground surface, even though only few studies with this 
97 configuration have been focused on the understanding of the dynamics of the 98 water front during irrigation (e.g., Galagedara et al., 2005; Moysey, 2010; Mangel et 99 al., 2012; Lai et al., 2012) or using natural rainfall (Busch et al., 2014). When 100 working solely from the ground surface, three approaches are possible to 101 determine soil moisture content: (a) use the velocity of the direct ground wave, (b) 102 estimating velocity from the reflected events, (c) estimating impedance and thus 103 velocity from the reflected GPR signal. Approaches (a) and (b) share in fact the 104 same operational characteristics, needing the two antennas to be separated from 105 each other. Approach (c) does not require antenna separation and exploits the 106 physics of the reflection mechanism, with its own advantages and disadvantages 107 (e.g., Lambot et al., 2004; Schmelzbach et al., 2012), and with more limited 108 applications so far. When the two antennas are separated from each other, the 109 survey can be conducted in wide angle reflection and refraction (WARR) mode 110 (e.g., van Overmeeren et al., 1997), where one antenna is kept fixed while the other 111 is moved, or common mid point (CMP) (Fisher et al., 1992; Greaves et al., 1996;

112 Steelman et al., 2012), where both antennas are moved simultaneously to keep the 113 same mid-point. Both sounding techniques allow for a good identification of direct 114 waves through the air and the ground. These methods are also employed for the 115 estimation of velocity from the reflected events, even though for this use the 116 normal move-out approach, typical of seismic processing, may not be ideal (see 117 Becht et al., 2006 for a discussion). The estimation of velocity from the direct wave 118 through the ground is the most widely adopted approach for vadose zone 119 applications (e.g. van Overmeeren et al., 1997; Huisman et al., 2001; Hubbard et al., 120 2002). However, in some cases direct arrivals are not so straightforward to 
121 identify and can be confused with other events. This can happen in the presence of

122 critically refracted radar waves (Bohidar and Hermance, 2002) or guided waves

123 (Arcone et al., 2003; van der Kruk et al., 2006; Strobbia and Cassiani, 2007). A

124 water front that infiltrates from the surface can give rise to such ambiguous

125 situations, as the wet and consequently low velocity layer, lying on top of a faster

126 (drier) media, can give rise to critically refracted waves (Bohidar and Hermance,

127 2002) as well as act as a waveguide confined between two faster layers: the air

128 above and the drier media below (Strobbia and Cassiani, 2007), the two situations

129 being defined by the ratio between the wavelength and the layer thickness.

130 Therefore, to study infiltrating fronts, maximum care must be given in

131 understanding the nature of the observed, multi-offset GPR signal, possibly

132 exploiting the entire information content of the data (e.g. Busch et al., 2012).

133 ERT measurements (Binley and Kemna, 2005) have been widely employed to

134 monitor water dynamics, as variations of moisture content (Daily et al., 1992;

135 Binley et al., 1996) and salinity of pore water (Perri et al., 2012) leads to changes in

136 the electrical properties of the media (La Brecque et al., 2004; Cassiani et al.,

137 2009a). However, it is well known that resolution limitations (Day-Lewis et al.,

138 2005) can produce severe mass balance errors (Singha and Gorelick, 2005) even in

139 the most favorable cross-hole configurations. The problem is even more serious

140 when only surface ERT are used to monitor natural or artificial irrigation from the

141 ground surface (Michot et al., 2003; Clément et al., 2009; Caputo et al., 2012;

142 Cassiani et al., 2012; Travelletti et al., 2012) where resolution dramatically drops

143 with depth and a direct conversion of inverted resistivity values into estimates of

144 soil moisture content may prove elusive. 
145 Geophysical measurements can be informative of the hydrological response of the

146 soil and subsoil if applied in time-lapse monitoring mode: some geophysical

147 quantities (in this case, $\rho$ and $\varepsilon_{\mathrm{r}}$ ) are useful indicators of changes in the

148 hydrological state variables, such as moisture content or pore water salinity.

149 However, in order to extract this hydrological information, the assimilation of

150 measurements in a hydrological model is needed. Two different approaches may

151 be applied, named respectively "uncoupled" and "coupled" hydro-geophysical

152 inversions (Ferré et al. 2009; Hinnell et al., 2010). The procedure for an uncoupled

153 inversion can be summarized by the following steps:

154 1. the spatial distribution of the geophysical quantity of interest (e.g. electrical

155 resistivity for ERT) is derived from the inversion of geophysical field data;

156 2. the application of a petro-physical relationship leads to obtaining, from the 157 geophysical quantity, an estimation of moisture content distribution;

158 3. the estimated hydrologic state variable, in its spatio-temporal distribution, 159 is used to calibrate and constrain a hydrological model, thus identifying the $160 \quad$ corresponding governing parameters.

161 The inversion of geophysical measurements is usually an ill-posed inversion 162 problem that can be tackled introducing prior information. If no solid independent 163 information is available, the most common approach is the introduction of a 164 regularizing functional, commonly a smoothness constraint (Menke, 1984). As a 165 consequence of ill-posedness and regularization, the inversion procedure can lead 166 to artifacts, misinterpretations and unphysical results, especially in the subsurface 167 regions where the sensitivity of the measurements is low (consider e.g. Day Lewis 
168 et al., 2005). To overcome these problems, a coupled hydro-geophysical modeling

169 can be applied:

170 1. a hydrological model is used to predict the evolution of hydrological state 171 variables - e.g. moisture content - on the basis of a set of hydrological 172 governing parameters, the identification of which is the final aim of the 173 inversion;

174 2. a suitable petrophysical relationship (same as for point (2) above) 175 translates hydrological state variables into geophysical quantities, such as 176 resistivity or dielectric permittivity;

$1773 . \quad$ the simulated geophysical quantities are used to predict the geophysical 178 field measurements;

179 4. a comparison between predicted and measured geophysical field 180 measurements allows a calibration of the complex of hydrological and 181 geophysical models (thus the name "coupled inversion"), leading to the 182 identification of the hydrological parameters, that is the key objective of the 183 study.

184 In this work we follow a coupled approach within the framework of data 185 assimilation (DA). DA schemes are mathematical tools of common use in 186 hydrological applications. The main idea behind DA is using the field 187 measurements to correct numerical simulations obtained with a hydrological 188 model, thus modifying their governing parameters. This is possible by the 189 recursion of forecast steps, which simulate the time-evolution of the probability 190 density function (pdf) of the hydrological process, and analysis (or update) steps, 191 which compute a posterior pdfs of the model parameters and state variables by 
192 assimilating the measurements (e.g., McLaughlin, 2002; Moradkhani et al., 2005). A

193 few examples of coupled hydro-geophysical inversion exist in the literature (e.g.,

194 Busch et al., 2014) but the use of DA techniques is less widespread (Rings et al., 195 2010; Tran et al., 2014).

196 The present work focuses on a field experiment where artificial irrigation is 197 monitored in time-lapse mode from the surface via both ERT and GPR. The 198 homogeneous nature of the site, made of aeolic sand deposits, provides a 199 simplified case study suitable to evaluate the performance of coupled hydro200 geophysical inversion and test the information content of different geophysical 201 data. Both GPR and ERT geophysical measurements are assimilated into the 202 hydrological model CATHY (Camporese et al., 2010), that is employed for the 203 numerical simulation of the experiment. We elected to use the iterative sequential 204 importance resampling (SIR) proposed by Manoli et al. (2015) as a DA technique to 205 estimate the model saturated hydraulic conductivity. This technique is particularly 206 designed to assimilate geophysical measurements in a coupled hydro-geophysical 207 model: the geophysical measurements are blended in the simulation to update the 208 state of the system, estimate the model parameters and quantify the model 209 uncertainties.

210 The specific goals of this work are:

211 1. to analyze in detail the nature of the WARR GPR data collected during the 212 irrigation experiment, verifying whether or not complex refraction and 213 waveguide phenomena occur during the progression of the wetting front, 214 and how and to what extent this type of data can be processed and inverted; 
215 2. to assess the effectiveness of incorporating ERT and GPR data in a coupled hydro-geophysical inversion procedure that, using the unsaturated flow equations, point directly at the estimation of the saturated hydraulic

3. to evaluate to what extent the information that can be obtained from GPR conductivity, and to compare this approach with the results of a classical uncoupled inversion approach;

The paper is organized as follows: Section 2 is dedicated to the description of the hydrological model and the DA procedure used for the coupled inversion of the 227 geophysical data. After presenting the hydrological experiment taken into 228 consideration (Section 3), in Sections 4 and 5 we analyze the GPR and ERT data, respectively. In Section 6 we describe the setup for the DA procedure in this experiment. The benefits of the coupled inversion are presented in Section 7. The major conclusions of this work are summarized in Section 8.

\section{DATA ASSIMILATION}

234 Data Assimilation methods are typically made of three components: 1) a 235 forward model describing the dynamics of the physical process under study, 2) an 236 observation model that links the simulated system variables to the observed data, 237 and 3) the update procedure, that changes the simulated variables on the basis of 238 the observations. This section describes these three components for our particular 
239 application, i.e., the assimilation of ERT and GPR data to calibrate an unsaturated

240 hydrological model with the iterative SIR method.

241

\section{$242 \quad \underline{2.1}$ Hydrological model}

243 The infiltration process in a variably-saturated isotropic porous medium is 244 described by the Richards' equation:

$$
S_{s} S_{w}(\psi) \frac{\partial \psi}{\partial t}+\phi \frac{\partial S_{w}(\psi)}{\partial t}=\vec{\nabla} \cdot\left[\boldsymbol{K}_{s} K_{r}(\psi)\left(\vec{\nabla} \psi+\eta_{z}\right)\right]+\mathrm{q}
$$

245 where $S_{s}$ is the elastic storage term $\left[\mathrm{m}^{-1}\right], S_{w}$ is water saturation [-], $\psi$ is water 246 pressure head/suction [m], $t$ is time [s], $\phi$ is porosity [-], $\boldsymbol{K}_{\boldsymbol{s}}$ is the saturated 247 hydraulic conductivity [ $\mathrm{m} \mathrm{s}^{-1}$ ] tensor, $K_{r}$ is the relative hydraulic conductivity [-], $248 \eta_{z}=(0,0,1)^{T}$ with $z$ the vertical coordinate directed upward, and $q$ is a 249 source/sink term [s-1 ${ }^{-1}$. Eq. (1) is highly nonlinear due to the dependencies of soil 250 saturation and relative hydraulic conductivity on pressure head. These terms are 251 modeled using the water retention curves proposed by van Genuchten and Nielsen 252 (1985).

253

$254 \quad \underline{2.2 \text { Geoelectrical and GPR models for data assimilation }}$

255 The electrical potential field induced in the soil by current injection during the 256 ERT survey, $\Phi[\mathrm{V}]$, can be modeled as:

$$
-\vec{\nabla} \cdot\left[\rho^{-1} \vec{\nabla} \Phi\right]=I\left[\delta\left(\vec{r}-\vec{r}_{S+}\right)-\delta\left(\vec{r}-\vec{r}_{S_{-}}\right)\right]
$$

257 where $\rho$ is the electrical resistivity of the soil $[\Omega \mathrm{m}], I$ is the applied current $[\mathrm{A}], \delta$ is 258 the Dirac function, $\vec{r}=(x, y, z)$, and $\vec{r}_{S+}$ and $\vec{r}_{S-}$ are the source and sink electrode 
259 positions, respectively. Here, the geophysical model is linked to the hydrologic

260 model by the petrophysical relationship proposed by Archie (1942):

$$
\rho\left(t_{i}\right)=\rho\left(t_{0}\right)\left(\frac{S_{w}\left(t_{0}\right)}{S_{w}\left(t_{i}\right)}\right)^{n}
$$

261 where $S_{w}\left(t_{0}\right)$ is the background water saturation degree and $\rho\left(t_{0}\right)$ is the 262 corresponding bulk electrical resistivity of the soil. In Eq. (2) the bulk electrical 263 resistivity at $i$-th measurement time, $\rho\left(t_{i}\right)$, can be predicted by the knowledge of 264 the saturation degree at the same time step, $S_{w}\left(t_{i}\right)$, and vice-versa. Thanks to Eqs. 265 (2) and (3), we can write the ERT measurements, here indicated with $y_{\mathrm{ERT}}\left(t_{i}\right)$, as a 266 nonlinear function $H_{E R T}$ of the water saturation:

$$
y_{\mathrm{ERT}}\left(t_{i}\right)=H_{E R T}\left(S_{w}\left(t_{i}\right)\right)+v_{E R T}\left(t_{i}\right)
$$

267 where $v_{E R T}\left(t_{i}\right)$ represents a Gaussian measurement error with variance $R_{E R T}\left(t_{i}\right)$, $268 v_{E R T}\left(t_{i}\right) \sim N\left(0, R_{E R T}\left(t_{i}\right)\right)$.

269 For linking the GPR data to the hydrological model we adopt a simplified 270 approach. The observation model that links the numerical simulations to the GPR 271 measurements consists in the estimation of the infiltration front depth from the 272 simulated vertical profiles of water saturation. When the considered porous media 273 can be considered spatially uniform and the irrigation rate is nearly constant in 274 time, at any assimilation time $\left(t_{1}, t_{2}\right.$ or $\left.t_{3}\right)$ the water saturation can be considered 275 uniform from the surface down to a certain depth $d_{1}$, while from $d_{1}$ to a depth $d_{2}$ it 276 decreases to the initial saturation value according to the soil water retention curve, 277 and finally the water content remains practically constant from $d_{2}$ to the bottom of 278 the domain (considering that the water table is much deeper than the vertical 279 extent of the infiltration domain). The average value of the two depths $d_{1}$ and $d_{2}$ is 
an approximation of the depth of the simulated infiltration front. Indicating the estimated infiltration front with $y_{\mathrm{GPR}}\left(t_{i}\right)$, from the described procedure we have 282 that:

$$
y_{\mathrm{GPR}}\left(t_{i}\right)=H_{G P R}\left(S_{w}\left(t_{i}\right)\right)+v_{G P R}\left(t_{i}\right)
$$

283 where $H_{G P R}$ is nonlinear operator and $v_{G P R}\left(t_{i}\right)$ is a Gaussian measurement error

284 with with variance $R_{G P R}\left(t_{i}\right), v_{G P R}\left(t_{i}\right) \sim N\left(0, R_{G P R}\left(t_{i}\right)\right)$. In the DA process $y_{G P R}\left(t_{i}\right)$ is 285 compared with the average thickness estimated from GPR measurements.

286 More accurate (and more complex) GPR modeling could be conducted to 287 construct a forward model e.g. based upon a full-waveform approach (see e.g. 288 Klotzsche et al., 2012, 2013). However we do not deem this is necessary for this 289 case study, where the key information that is derived from GPR resides in the 290 depth of the infiltration front and the electromagnetic (EM) wave propagation is 291 dominated by guided waves (see Section 4).

\section{$\underline{2.3}$ Iterative SIR algorithm for Data Assimilation}

294 In Manoli et al. (2015) the hydrological and geophysical models are coupled in a 295 DA framework to simulate ERT surveys and update the physical state variable (soil 296 saturation) and the model parameters whenever a geophysical measurement is 297 available. DA methods allow the incorporation of real system observations onto 298 the dynamical model to automatically correct the model forecast (i.e., the solution 299 of Eq. 1) and the model parameters (e.g., the saturated hydraulic conductivity $\boldsymbol{K}_{\boldsymbol{s}}$ ) 300 thus reducing the uncertainties related to the model prediction. In the following 301 we indicate with $\lambda$ the set of time-independent model parameters in Eq. (1) and 302 with $p_{0}(\lambda)$ its prior pdf. 
The SIR algorithm uses a weighted Monte Carlo (MC) approach to perform the state and parameter update (e.g., Moradhkani et al., 2005). The MC realizations,

305 which are also called particles, are initialized by sampling the parameter values

306 from the prior distribution, $\left\{\lambda_{0}^{j}\right\}_{j=1}^{N}$, where $N$ is the total number of MC realizations 307 and $j$ is the realization index. SIR associates a weight to each realization, $w_{0}^{j}$, which 308 is initialized to $1 / N$. The forecast step is given by the numerical solution of 309 Richards's equation (1) for each set of parameters, thus describing the space and 310 time evolution of the infiltration process. Note that weights and parameters are 311 invariant during the forecast step. At a general time $t$, each realization is described 312 by its particular set of parameters, state variables and weight $\left\{\lambda_{t}^{j}, S_{w}^{j}(t), w_{t}^{j}\right\}_{j=1}^{N}$.

313 In an assimilation step $t_{i}$, with the idea that the weight represent the 'closeness' 314 of a realization to the real process, the SIR algorithm changes the weights 315 according to the Bayes' formula: new weights are assigned to each particle on the 316 basis of the likelihood function of the measured data with respect to the simulated 317 data, e.g., $p\left(y_{E R T}\left(t_{i}\right) \mid S_{w}^{j}\left(t_{i}\right)\right)$ for ERT data. The likelihood functions for the ERT and 318 GPR data can be obtained from the measurement error pdfs described Eqs. 4 and 5, 319 respectively. Then, the weights are changed with the following formula (here 320 written for a general observation $y$ ):

$$
\begin{gathered}
\widetilde{w}_{t_{i}}^{j}=w_{t_{i-1}}^{j} p\left(y\left(t_{i}\right) \mid S_{w}^{j}\left(t_{i}\right)\right) \\
w_{t_{i}}^{j}=\frac{\widetilde{w}_{t_{i}}^{j}}{\sum_{j=1}^{N} \widetilde{w}_{t_{i}}^{j}}
\end{gathered}
$$

321 where (7) is a normalization of the weights. Since some of the updated weights 322 may be negligible, meaning that the corresponding particles are not representative 
323 of the physical process, the SIR introduces a resampling step after the update. In

324 the resampling step, the particles with negligible weights are discarded, while 325 those with large weights are duplicated, in order to retain only the particles that 326 are more representative of the filtering probability. Manoli et al. (2015), similarly 327 to Moradhkani et al. (2005), adapted this step to update also the model 328 parameters: the weighted empirical distribution of the parameters is adopted to 329 sample new parameter values the duplicated particles. The SIR method continues 330 with a repetition of forecast and update steps, and terminates in correspondence 331 of the last geophysical measurement. Since bias may be present in the initial model 332 parameters, and since the hydraulic conductivity distribution may not converge 333 during the sequential assimilation, the posterior distribution computed with the 334 SIR method may not be optimal for the whole simulation. For this reason it is

335 fundamental to iterate the described procedure until the parameter distribution is 336 unchanged during the simulation. At each iteration the procedure initializes the 337 parameters with an averaged posterior distribution, computed on the ensemble of 338 the hydraulic conductivities computed after all the previous updates.

\section{FIELD SITE AND IRRIGATION EXPERIMENT}

The experimental site is located in the campus of the Agricultural Faculty of the

342 University of Turin, Italy, in Grugliasco ( $45^{\circ} 03^{\prime} 52^{\prime \prime} \mathrm{N}, 7^{\circ} 35^{\prime} 34^{\prime \prime}$ E, $290 \mathrm{~m}$ a.s.l.)

343 (Fig.1). The depth of interest is the top $1 \mathrm{~m}$ from the ground surface, where the 344 lithology is homogeneous. The stratigraphy is composed of a regular sequence of 345 sandy soil (mesic Arenic Eutrudepts) and the sediments in this area are largely 346 aeolic sands with extremely low organic content. The aeloic sand grains are 
347 relatively homogeneous in size with a mass median diameter $\left(d_{50}\right)$ of about $200 \mu \mathrm{m}$

348 and porosity ranging between 0.35 and 0.4 (Cassiani et al., 2009c). According to

349 the Comprehensive Soil Classification System, the horizon down to about 1-1.5

350 meter depth is an A-horizon made of mineral matter ( $80 \%$ sand, $14 \%$ silt and $6 \%$ 351 clay).

352 The water table is located around $20 \mathrm{~m}$ below the ground surface and therefore 353 the shallow vadose zone, where our experiment took place, is not practically 354 influenced by the underlying saturated zone. At the moment of the survey the 355 vegetation was composed only of natural grass, no cultivation is present (Fig. 1b).

356 An infiltration experiment was performed at the site on August 28, 2009. The 357 irrigation was provided by a $17 \mathrm{~m}$ line of sprayers. The soil surface covered by 358 irrigation was approximately a rectangle of $18 \mathrm{~m}$ by $2.6 \mathrm{~m}$ (Fig. 1). The irrigation 359 lasted for 5 hours and 45 minutes and was performed in 3 steps (Table 1), 360 separated by intervals when a break of the irrigation allowed ERT and GPR 361 acquisitions to be performed (see Fig. 1c for the geometry of the geophysical 362 surveys). At the center of the ERT profile, along the sprinkler line, two Time 363 Domain Reflectometry (TDR) probes were vertically placed in the soil with a 364 length of 0.15 and $0.30 \mathrm{~cm}$.

365 The irrigation intensity was always lower than the infiltration capacity of the 366 soil, so no ponding was observed at the soil surface. The ERT and GPR 367 measurements were performed with the schedule summarized in Table 2, where 368 the time is referred to the starting of the irrigation. 


\section{GPR DATA ANALYSIS}

The infiltration test was monitored by GPR using a PulseEkko Pro radar system (Sensors and Software Inc., Canada) with $100 \mathrm{MHz}$ antennas. The surveys were repeated in time (Table 2) using a WARR scheme. The WARR profiles were acquired along the sprinkler line (Fig. 1c); the time sampling interval was $0.2 \mathrm{~ns}$ and the offset increment between transmitting and receiving antennas was equal to $0.1 \mathrm{~m}$ over a $10.5 \mathrm{~m}$ line, starting from an initial offset (minimal distance between transmitter and receiver) of $1 \mathrm{~m}$.

The background WARR radargram before the irrigation is shown in Fig. 2, where we can clearly recognize the direct ground wave with a velocity of about $0.14 \mathrm{~m} / \mathrm{ns}$. The evolution of WARR surveys over time (Fig. 3) shows that the infiltration front modifies substantially the appearance of the GPR signal. The radargrams in Fig. 3 are distinctly different from each other: the direct radar wave in air is obviously unaltered over time, while the signal from the soil is progressively delayed. This phenomenon is due to the presence of a wet lowvelocity layer, between the surface and the dry sandy soil, which becomes increasingly thicker over the irrigation period. At a first glance, the interpretation of the data may be conducted by identifying the first soil arrival as a critically refracted GPR wave that comes from the - wet - dry interface and arrives at larger intercept times as infiltration progresses, consistently with a deeper wetting front. Although, this event must be present in the data, it is likely to be masked by guided modes of GPR wave propagation as described by Strobbia and Cassiani (2007). The establishment of guided EM waves is the consequence of the geometry of the dielectric properties of the materials involved in the wave propagation. The energy 
395 radiated from the transmitting antenna is spread out into the low-velocity layer

396 and reaches the underlying faster layer (dry sand) with an angle greater than the 397 corresponding Snell critical angle, in such a way that the energy is totally reflected. 398 The same phenomenon happens when the reflected energy reaches the boundary 399 between the air and the wet sandy media. The total internal reflections guide the 400 GPR waves horizontally inside the low-velocity layer, while outside of the wet layer 401 there are only evanescent waves with no radiation in the dry material and in the 402 air. A simpler interpretation of the radargrams (Fig. 3A) as a simple consequence 403 of refracted events - albeit possible (see Cassiani et al., 2009b) - would lead to 404 unclear event identification.

405 We analyzed the frequency-wavenumber $(f-k)$ spectra of the radargrams with 406 the aim of recognizing guided modes of wave propagation (Fig. 4A). The $f-k$ spectra 407 are obtained by a preprocessing involving several filtering procedures. The first 408 preprocessing step consists in the application of a de-wow filter, following the 409 procedure of Gerlitz et al. (1993). The wow effect is due to the air-ground pulse 410 interference. In fact, electrostatic and inductive fields near the transmitter lead to 411 the saturation of the receiver electronics and generate a low frequency 412 contribution that decays with distance. The consequence of the wow is to move 413 trace amplitude towards positive (or negative) values, resulting in a non-zero414 mean trace. Removing the wow frequencies should reconstruct a zero-mean trace, 415 where small amplitudes are easier to identify. This filter is based on the 416 subtraction of the median amplitude, calculated inside a mobile window in the 417 time domain. The window size is determined from the maximum wow frequency, 
418 achieved from the frequency spectra of all unfiltered traces $(f$ - $x$ spectra - i.e. one 419 frequency spectrum for each offset $\mathrm{x}$ ).

420 The second processing step is a muting of the portions of the radargram that are

421 not relevant in the guided mode propagation, so as to highlight the signal of the 422 supposed guided waves. The muting process has the aim of cleaning those portions 423 of the radargrams that are not useful in the present study: events that may be 424 considered as noise in a guided wave analysis. So muting is applied to remove the 425 air direct wave as well as the reflected events at later times. We applied a Tukey 426 window in time, to prevent ringing in the $f-k$ domain that may be due to an abrupt 427 signal step in the time domain. The Tukey window is set to obtain half of the entire 428 window length as a flat plateau, while the two marginal sectors consist of segments 429 of a phase-shifted cosine.

430 The final filtering process is the application of a finite impulse response (FIR) 431 filter to remove signal noise at low and high frequencies. The FIR filter has a 432 structure that can maintain the true intensity of the signal between 20 and 250 433 MHz. This is a broad window for a signal centered around $100 \mathrm{MHz}$, since the 434 guided propagation shows apparent frequencies that can be higher than the 435 acquisition capabilities of the receiving antenna. This fact is the consequence of the 436 limitation of our array, that records the GPR echoes only at the ground surface.

437 The filtered radargrams are shown in Fig. 3B. The corresponding $f-k$ spectra (Fig. 438 4A) show the signal evolution over time. The color scale of the power spectral 439 density is the same for the different time-steps, in order to show the differences of 440 energy distribution over time. The energy peaks at times $t_{1}$ and $t_{3}$ have much 441 higher amplitudes than at time $t_{2}$, when energy peaks are relatively weak as energy 
442 is spread over several modes of propagation, while at times $t_{1}$ and $t_{3}$ a dominant

443 mode is clearly recognizable. This may be the consequence of our spatial sampling

444 that is not able to record with enough intensity the prevailing mode of resonance

445 induced by that particular subsoil geometry, but can also be a symptom of the 446 energy shifting between fundamental (at time $t_{1}$ ) and first higher mode (at time $t_{3}$ ).

447 The positions of the absolute maxima, detected for each frequency, are plotted as 448 magenta dots (Fig. 4A), while the white dots represent the local maxima.

449 Maxima picking in spectral amplitudes leads to obtaining the dispersion curves 450 of Fig. 4B, showing the dependence of phase velocity on frequency. Here red dots 451 correspond to the absolute maxima, while blue dots show local maxima. The 452 dispersion curves at times $t_{1}$ show a clearly identifiable fundamental mode, while 453 at time $t_{3}$ the first higher mode is much more energetic than the fundamental mode. 454 The switch of the highest energy to higher modes of propagation may lead to the 455 transient step which involves time $t_{2}$, where the power spectral density is spread 456 upon different modes (Fig. 4A).

457 In order to give a hydrological meaning to these results, we need to translate the 458 spectral analysis of guided waves into an estimate of the evolution of the hydraulic 459 process. In particular we are interested in the location of the wetting front at depth, 460 as this information is suitable for the calibration of hydrological models. The depth 461 of this front corresponds to the thickness of the guiding high dielectric permittivity 462 layer. The identification of the layer thickness and dielectric properties requires 463 inversion of the dispersion curves (van der Kruk et al., 2006; Strobbia and Cassiani, 464 2007). We adopted as a forward model the description of the asymmetric slab 465 waveguide given by Strobbia and Cassiani (2007). The approximation of 1- 
466 dimensional waveguide is valid as long as we assume that irrigation is practically 467 uniform along the sprinklers' line, and the soil is largely homogeneous. The 468 inversion of dispersion curves was performed using a MC approach. We sampled 469 the controlling parameters, i.e.: velocity of the shallower wet layer, velocity of the 470 deeper dry layer and thickness of the wet layer. The velocity of air can be 471 considered a constant equal to $0.3 \mathrm{~m} / \mathrm{ns}$. To reduce the number of ensembles of 472 parameters combinations, we fixed the value of the velocity of the deeper and 473 faster layer to about $0.14 \mathrm{~m} / \mathrm{ns}$, i.e. we set it equal to the velocity of the soil before 474 irrigation (Fig. 2). This choice is also in accordance with the TDR measurements 475 (0.3 m prongs) performed before the irrigation, showing a dielectric permittivity of 4764.55 , which corresponds to a EM wave velocity of $0.141 \mathrm{~m} / \mathrm{ns}$. The forward model 477 of EM wave propagation assumes the presence of only two ground layers, so we 478 are not able to simulate a smoothed wetting front, that is approximated as a sharp 479 discontinuity of dielectric permittivity. The thickness range is fixed, for all times, 480 between $0.3 \mathrm{~m}$ and $1 \mathrm{~m}$, with an increment of $0.05 \mathrm{~m}$. The velocity of wet layer is 481 sampled in the interval from $0.065 \mathrm{~m} / \mathrm{ns}$ to $0.1 \mathrm{~m} / \mathrm{ns}$, at steps of $1.05 \times 10^{-4} \mathrm{~m} / \mathrm{ns}$. 482 Both fundamental and first modes are simulated, setting all possible combinations 483 of the parameter space for a total of about 47000 simulations.

484 Fig. 5 shows the results of the inversion procedure, where the goodness of fit 485 between experimental and simulated dispersion curves is calculated using the 486 Nash-Sutcliffe index (NSI) (Nash and Sutcliffe, 1970). Fig. 5A reproduces the 487 experimental curve (black dotted line) plotted together with the best-fitting 488 synthetic curves: the light gray lines have NSI values between 0.85 and 0.95 , while 489 the dark gray lines show NSI $>0.95$. At time $t_{1} 1035$ curves of the fundamental 
490 mode have a NSI $>0.95$. At time $t_{2}$ the fitting of the measured dispersion curve for

491 the fundamental mode is poor, as NSI does not exceed, for any curve, the value of

492 0.87. For this reason we consider in Fig. 5 only the 1124 simulations with NSI $>0.85$.

493 The 1232 synthetic curves of the first higher mode are used to represent the 494 experimental first mode at time $t_{3}$, where the NSI is greater than 0.95 . We inverted 495 the first higher mode for time $t_{3}$, as at this time the higher mode is much more 496 energetic than the fundamental mode, as shown by Fig. 4. Fig. 5B-C show the 497 distribution of the parameters linked to the best simulations: wet layer thickness 498 and wet layer velocity, respectively.

499 We averaged the parameters of the best simulations to achieve an estimated 500 value for both the velocity and the thickness of the wet layer, at all times. Statistics 501 and ranges of the considered best simulations are summarized in Table 3 . The 502 velocity of the wet layer changes slightly over time, with values confined in a 503 narrow range, in all cases very far from the value of the dry sand $(0.14 \mathrm{~m} / \mathrm{ns})$.

504 We are less confident in the inversion of time $t_{2}$ for two reasons: (1) the fitting 505 between measured and calculated data is poor respect to the other time-steps that 506 show high values of NSI; (2) the experimental dispersion curve is derived from the $507 f-k$ domain, that shows that energy is smeared between fundamental and first 508 higher mode. Therefore, the dispersion curve at time $t_{2}$ may be heavily affected by 509 the unfavorable signal to noise ratio for both the fundamental and the first higher 510 mode.

511 It should also be noted that our MC inversion provides a view of the degree of 512 correlation of the two governing parameters (thickness and velocity of the wet 513 layer). Fig. 6 shows the levels of NSI>0.85 plotted in the parameter space, 
514 highlighting some degree of positive correlation. However, at times $t_{1}$ and $t_{3}$ the 515 best fitting simulations (NSI $>0.984$ for $t_{1}$, NSI $>0.987$ for $t_{3}$ ), marked as a green area, 516 are centered around small parameter ranges. At time $t_{2}$ the green area highlights

517 the simulations with NSI $>0.886$. Table 3 reports the standard deviations of the 518 parameters associated to the best-fitting simulations that are quite small with 519 respect to the average values.

520

521 5. ERT DATA ANALYSIS

522 The ERT data were collected at the surface using a Syscal-Pro resistivimeter 523 (IRIS Instruments, France). Twenty-four electrodes spaced $20 \mathrm{~cm}$ were placed on a 524 transect perpendicular to the sprinklers' line, for a total length of $4.6 \mathrm{~m}$ (Fig. 1). 525 The acquisition scheme was a dipole-dipole skip zero (dipoles with minimal 526 distance equal to one electrode spacing). Reciprocal measurements were acquired 527 and processed to estimate data errors. All the reciprocal measures with the 528 statistical operator RSD (Relative Standard Deviation) exceeding the $5 \%$ were 529 removed from the dataset. This reciprocal error analysis leads to a different 530 dataset for each time step. For this reason and to have comparable results, we 531 performed the inversions considering only the quadripoles that are present in all

532 datasets. The common datasets preserve 200 measurements over a total of 231 533 quadripoles, thus data quality is particularly good. We inverted the data as the 534 ratio of electrical resistances at a specific time with respect to the resistance values 535 at the background measurement (in our case the time-step before the irrigation):

$$
R=\frac{R_{i}}{R_{0}} \cdot R_{h o m}
$$


536 Where $R_{i}$ is the electrical resistance at the $i$-th time-step, $R_{0}$ is the electrical

537 resistance at the background measure and $R_{h o m}$ is the electrical resistance for a

538 homogenous space of $100 \Omega \mathrm{m}$. All the electrical resistances are referred to the

539 same quadripole and $R$ is calculated for each measurement in the dataset. As data

540 errors are difficult to estimate in terms of resistance ratios, some degree of

541 arbitrary choice is present in ratio inversion. Fig. 7A shows the inversion of the

542 resistivity ratios with respect to background (Eq. 8) applying a smoothness

543 constrain of $3 \%$.

544 This time-lapse ratio inversion clearly shows the variation of the electrical

545 resistivity during the experiment (Fig. 7A). The results of the inversion are sections

546 of the percentage variation of resistivity respect to the background values: values

547 equal to $100 \Omega \mathrm{m}$ correspond to unchanged resistivity, while values less or more

548 than $100 \Omega \mathrm{m}$ show a decreasing or an increasing resistivity, respectively. The

549 inversions were performed using the 2D code developed by Andrew Binley

550 (http://www.es.lancs.ac.uk/people/amb/Freeware/Freeware.htm; Slater et al.

551 2000; Cassiani and Binley, 2005; Linde et al., 2006).

552 Fig. 7B shows the results of the ratio of the inverted absolute profiles with

553 respect to the inversion of the background survey. In this case the profiles are

554 inverted with a data error set at 5\%, consistent with the reciprocal error removal

555 procedure, and then a pixel by pixel ratio is computed. From the comparison

556 between Fig. 7A and 7B it is apparent that the two approaches are, in this case,

557 essentially equivalent at showing the evolution of the infiltration process. This

558 similarity corroborates the hypothesis of the 2D symmetry of the infiltration 
559 process along the sprinkler line, since the ERT monitoring is performed on 2D

560 profiles, assuming a homogeneous resistivity distribution on the third direction.

561 In Fig. 7 the infiltration process is clearly visible. The plume of injected fresh

562 water increases moisture content and consequently reduces resistivity. The shape

563 of the plume is the consequence of a non-uniform distribution of irrigation in the

564 direction perpendicular to the sprinklers' line. The distribution of the artificial

565 precipitation is more likely Gaussian in shape, with considerably more water

566 dropping close to the sprinklers. Time-steps $t_{5}$ and $t_{7}$ are not shown, as only

567 modest variations are present at these late times after the end of the irrigation.

568

569 6. SETUP OF THE COUPLED INVERSION

570 In this work the modeling based on the coupled-inversion described in Section 2 is

571 aimed specifically at the estimation of soil saturated hydraulic conductivity. The

572 physically-based hydrological model CATHY (Camporese et al., 2010) is employed

573 for the numerical solution of Eq. (1) and the simulation of the infiltration

574 experiment. The van Genuchten's parameters necessary for the setup of the

575 numerical model were derived from laboratory experiments: residual saturation is

576 fixed at 0.003 and $\alpha$ (the inverse of the air entry suction) is equal to $5.4 \mathrm{~m}^{-1}$. These

577 values are derived from laboratory experiments and are not considered of

578 paramount importance in the context of the given infiltration experiment. Of

579 course a more complete parameter identification scheme could also include them,

580 as described by Manoli et al. (2015) in the context of using ERT data alone.

581 A careful analysis of Fig. 7 reveal that irrigation was not uniformly distributed in

582 the direction orthogonal to the sprinkler line, probably due to the presence of 
583 wind. This was taken into account in order to properly simulate the top boundary

584 conditions: the irrigation is modeled with a Gaussian distribution centered at 2.5

$585 \mathrm{~m}$, with variance equal to $0.6 \mathrm{~m}$, both values calculated such that the total flux

586 equals the real irrigation rate. The parameters of the Gaussian distribution are

587 fixed after a trial procedure where we matched the shape of the measured and 588 modeled plume (Fig. 7 and Fig. 10).

589 The parameters of Archie's law (Eq. 3), which are necessary to define the ERT 590 observation operator, are spatially uniform for considered field study. The 591 exponent $n$ is set to 1.27 as reported in Cassiani et al. (2009c), where the value is 592 obtained from laboratory calibration on the site's sediments. The initial soil 593 electrical resistivity $\rho\left(t_{0}\right)$ is set equal to $1300 \Omega \mathrm{m}$, based on the averaged value 594 obtained by the inversion of background ERT measures. In order to apply Eq. (3), 595 we need also an estimation of the initial volumetric water content, $\theta\left(t_{0}\right)$. For our 596 field experiment this is estimated from background GPR and TDR measurements. A 597 value $\theta\left(t_{0}\right)=0.07$ is obtained by applying the petrophysical relationship of Topp et 598 al. (1980):

$$
\theta=\left(-530+292 \varepsilon_{r}-5.5 \varepsilon_{r}^{2}+0.043 \varepsilon_{r}{ }^{3}\right) \cdot 10^{-4}
$$

600 where $\varepsilon_{r}$ is the bulk soil dielectric permittivity. A moisture content value of $7 \%$ 601 corresponds to $S_{w}\left(t_{0}\right)$ of 0.212 assuming a porosity of 0.33 as estimated by 602 Cassiani et al. (2009b) for the considered field sediments.

603 In this particular case, we are interested in the value of the saturated hydraulic 604 conductivity $\boldsymbol{K}_{\boldsymbol{s}}$, that is difficult to identify in unsaturated conditions by direct 605 measurements. The methodology presented in Manoli et al. (2015) describes $606 \boldsymbol{K}_{\boldsymbol{s}}$ with a lognormal probability distribution which mean and variance are updated 
607 at each assimilation time. Here, the prior values of the hydraulic conductivity mean 608 and variance are summarized in Table 5.

609 The iterative procedure is particularly advantageous when geophysical 610 measurements of different nature (e.g. ERT and GPR) are available for the 611 assimilation, as in the case we consider here. In fact, the independent assimilation 612 of different measurements is to prefer to the joint assimilation of the 613 measurements, since the latter requires the introduction of an artificial 614 normalization to weight the measurements.

615 In this paper the procedure is used to provide the "best possible" estimate of $616 \boldsymbol{K}_{\boldsymbol{s}}$ for the site using both ERT and GPR data. We adopt a strategy that is 617 particularly clear in assessing the information content of each dataset and of the 618 two datasets together. In particular, we produce the following four assimilation 619 schemes:

620 A. a scheme assimilating only ERT data (similar to the one proposed by Manoli $621 \quad$ et al., 2015);

622 B. a scheme assimilating only GPR data, based on the depth of the infiltration 623 front estimated from the guided wave analysis (see section 3);

624 C. a scheme that assimilates alternatively ERT and GPR leading to a final 625 estimate that accounts for both;

626 D. a scheme analogous to C, but using GPR and ERT in the reverse order - to 627 check convergence stability (the first iteration starts assimilating GPR data, 628 instead of ERT data).

629 The advantage of assimilating both ERT and GPR measurements is the 630 integration of different information. In this kind of experiment (irrigation 
631 monitored on the ground surface), the low sensibility of the ERT array at large

632 depths may be a disadvantage; so the infiltration front may be spread over a broad

633 area, since the most part of the energy is focalized along current paths that cross

634 the wet zone. GPR WARR surveys may be a useful addition to the information 635 obtained from ERT, as GPR can constrain the location of the water front at depth.

636

637 7. MODELLING RESULTS

638 The particle filter algorithm assimilates the geophysical data with four different 639 schemes (Fig. 8). Each assimilation scheme leads to a probability distribution of 640 the simulated parameters: in this case $\boldsymbol{K}_{\boldsymbol{s}}$ is the objective of the coupled inversion. 641 The evolution of the $\boldsymbol{K}_{\boldsymbol{s}}$ distribution during the assimilation procedures is 642 summarized in Fig. 8. For each assimilation scheme, 3 different prior $\boldsymbol{K}_{\boldsymbol{s}^{-}}$ 643 distributions are tested to verify the stability of the inversion procedure. It evinces 644 that the convergence towards the estimated $\boldsymbol{K}_{\boldsymbol{s}}$ value, at the end of the iteration 645 process, is not depending on the initial parameter's range.

646 The estimated values of $\boldsymbol{K}_{\boldsymbol{s}}$ are only slightly different from scheme to scheme: 647 for case $A: 1.010^{-5} \mathrm{~m} \mathrm{~s}^{-1}$, for case $B: 2.610^{-5} \mathrm{~m} \mathrm{~s}^{-1}$, for case $C: 1.110^{-5} \mathrm{~m} \mathrm{~s}^{-1}$, for case $648 D: 1.110^{-5} \mathrm{~m} \mathrm{~s}^{-1}$. Note that the differences in the estimated $\boldsymbol{K}_{\boldsymbol{s}}$ are almost negligible 649 for practical applications. Assimilating both ERT and GPR we obtain the same $650 K_{s}$ value, irrespective of the order of assimilation. The assimilation of only ERT 651 data (Fig. 8A) provides a $\boldsymbol{K}_{\boldsymbol{s}}$ estimate that is very similar to the ERT-GPR 652 assimilations. The assimilation of the GPR waterfront depths provides a value of $653 \boldsymbol{K}_{\boldsymbol{s}}$ about two times larger than the other estimates (Fig. 8B). We attribute this 
654 results to the large uncertainty associated to the GPR measurement and analysis, 655 in particular at the time $t 2$.

656 Forward hydrological models are then run with the estimated parameters and 657 the results are compared to the geophysical measurements (Tables 4 and 6). 658 Schemes $C$ and $D$ provide essentially the same hydrological model. The mean and 659 standard deviations of the posterior distributions for the four cases are listed in 660 Table 5 (together with the prior parameters).

661 In Table 4 the waterfront position inverted from the GPR signal is compared to 662 the simulated location of the saturation front. Note that the water front locations 663 estimated from the coupled inversions with the GPR assimilation leads to slightly 664 deeper water front estimations, while ERT and ERT-GPR assimilations conduct to 665 very similar results. The GPR contribution in the combined inversion with ERT 666 drives the estimated waterfront slightly deeper than estimated by ERT only. The 667 waterfront depths from GPR data alone are definitely more problematic to 668 interpret (see also Fig. 9), with uneven penetration speed between time intervals 669 1-2 and 2-3. Note that, as discussed in Section 3, time 2 is a problematic acquisition 670 for GPR, with energy spread over two modes and a more difficult estimation of 671 infiltration front depth.

672 The forward hydrological models are also compared against the ERT field 673 (resistance) dataset (Tab. 5). In this case the simulated hydrological states are 674 converted into geophysical quantities via Eq. 4, and a geophysical forward model 675 (Eq. 3) is run to obtain simulated ERT resistance data. Not surprisingly, the 676 forward model that best matches the field measurements is derived from the 677 assimilation of the sole ERT data. Anyway the assimilation of both ERT and GPR 
678 shows a very good fit to the measured ERT, while the assimilation scheme of only

679 GPR-derived waterfronts is distant from the information achieved from ERT 680 survey.

681 Fig. 9 shows the distribution of moisture content predicted by the flow models 682 with the parameters obtained from data assimilation. These saturation profiles are 683 compared against:

684 1. the moisture content profiles one could obtain by translating directly the 685 resistivity inverted images (Fig. 7) using the known Archie's law 686 parameters (Eq. 4).

6872 . the locations of the infiltration front as estimated from GPR inversion $688 \quad$ (Section 3).

6893 . 3 the estimation of the degree of saturation measured by TDR probes placed 690 at the mid-point of the ERT profile; relative dielectric permittivity is 691 translated into water content using Eq. (5).

692 There is no doubt that the data assimilated simulations are superior at providing 693 estimates of moisture content profiles that, while slightly different from each other, 694 are both consistent with data and model assumptions (most of all, mass balance 695 and hydraulic conductivity homogeneity).

696 The TDR data are used as validation of the modeled water saturation curves (Fig. 697 9). The values are consistent with the hydrological models, that show a rapidly698 moving saturation front at the first time steps. Unfortunately the TDR probes reach 699 the maximum depth of only $0.3 \mathrm{~m}$, so no information is available for the deeper 700 portions. 
701 For the sake of completeness, we also inverted the synthetic ERT data (Fig. 7C) 702 to provide a direct comparison with the $\rho$ distributions achieved by field 703 measurements (Fig. 7A). In addition, Fig. 10 shows the "true" resistivity structure 704 as simulated by the hydrological model in the combined ERT-GPR data 705 assimilation case. Comparing Figs. 7 and 10, note how inverted and "true" 706 resistivity images tend to diverge at late times, when the front reaches the deeper 707 zones where ERT has the lowest sensitivity, and inversion regularization takes 708 over and smears the images at depth. Consistently, the mass balance derived from 709 ERT data as calculated for the coupled and the uncoupled hydro-geophysical 710 inversions (Table 7) shows the weaknesses of the uncoupled approach for the 711 problem at hand. The uncoupled approach leads to a cumulative volume of injected

712 water over time that strongly overestimates the effective amount of irrigated 713 water.

714 Note that in the literature underestimation of mass balance is more commonly 715 observed (e.g., Singha and Gorelick, 2005), but this fact is dependent primarily on 716 the acquisition scheme and electrode geometrical configuration (e.g. cross-hole 717 versus surface measurements, as in this work).

\section{8. CONCLUSIONS}

720 Hydro-geophysical techniques are extremely useful in monitoring the 721 hydrological processes acting in the vadose zone and the data can be effectively 722 translated into hydrological quantities, particularly state variables such as 723 moisture content. The presented field case study analyzes a controlled irrigation 
724 test in an unsaturated subsoil with a plain terrain and nearly homogeneous sandy 725 soil.

726 The adopted hydro-geophysical methodology may strongly affect the results of

727 the hydro-geophysical inversion and consequently the hydrological parameter 728 estimations. An approach, that fully couples hydrological modeling and 729 geophysical measurements in a data assimilation procedure, leads to more 730 accurate results. Avoiding the geophysical inversion of the data, we reduce the 731 uncertainty in the hydrological quantities estimation, since no artifacts are 732 inserted in the method by solving an inverse problem. The errors that may be 733 present are due only to data acquisition and model choosing, as in any hydro734 geophysical issue. Of course an analysis of the inverted data is generally necessary, 735 not only to ascertain the data quality, but also to direct a correct choice of the 736 hydrological model needed to explain the data (see, e.g., discussion in Camporese 737 et al., 2011). One of the advantages of the coupled approach, that includes a 738 stochastic process, is the proper conservation of mass. This aspect is often a key 739 issue of the uncoupled approach, where the calibration of hydrological models via 740 geophysical inverted data may lead to inconsistent results that may jeopardize the 741 user's confidence in the method.

742 In the present field case both ERT and the infiltration front estimated with the 743 GPR data are considered in the data assimilation process, using a Sequential 744 Importance Resampling (SIR) that allows a flexible assimilation of either or both 745 datasets in a natural, non-subjective manner (i.e. without arbitrary weighting of 746 one dataset with respect to the other). From this procedure the information 747 content of each dataset in the assimilation procedure emerges naturally. 
In this particular case study, it is apparent that ERT data provide most of the

749 information needed to a robust hydraulic conductivity estimation. GPR, albeit

750 being apparently of easy interpretation in its time-lapse evolution (see Figure 3), at

751 a more in-depth quantitative analysis shows its intricacies linked to the inversion

752 of multi-modal dispersion guided waves. As the energy distribution over different

753 modes changes over time due to the changing geometry of the wet layer, the

754 inversion of GPR data requires particular attention and ultimately delivers weak 755 information on the infiltration process.

756 The comparison between coupled and uncoupled hydro-geophysical inversions 757 shows that, in this particular case, the latter is superior. This happens primarily 758 because the monitoring of type of experiment that we consider (irrigation and 759 infiltration from the ground surface) depends strongly on our ability to image the 760 processes honoring mass balance. In this respect, the uncoupled approach is not 761 capable of reproducing the real state of the system and consequently the mass 762 balance. The uncoupled approach may therefore lead to erroneous parameter 763 estimate. It should be noted how other problems may be less prone to suffering 764 from an uncoupled approach (see e.g. Camporese et al., 2011).

\section{ACKNOWLEDGEMENTS}

767 The authors would like to acknowledge support from the EU FP7 Collaborative 768 Projects CLIMB ("Climate Induced Changes on the Hydrology of Mediterranean 769 Basins - Reducing Uncertainty and Quantifying Risk"). This study was also funded 770 by the University of Padova, Italy, within the Research Programme "GEO-RISKS: 771 Geological, morphological and hydrological processes: monitoring, modeling and 
772 impact in the north-eastern Italy". Partial funding was also provided by the EU FP7

773 project GLOBAQUA ("Managing the effects of multiple stressors on aquatic

774 ecosystems under water scarcity").

775

776 REFERENCES

777 Archie GE. The electrical resistivity log as an aid in determining some reservoir $778 \quad$ characteristics. Trans. AIME 1942; 146: 54-62.

779 Arcone SA, Peapples PR, and Liu L. Propagation of a ground-penetrating radar 780 (GPR) pulse in a thin waveguide. Geophysics 2003; 68(6): 1922-1933.

781 ASTM D2487 - Standard Practice for Classification of Soils for Engineering $782 \quad$ Purposes (Unified Soil Classification System).

783 Becht A, Appel E, and Dietrich P. Analysis of multi-offset GPR data: a case study in a 784 coarse-grained gravel aquifer. Near Surf. Geophys. 2006; 4(4): 227-240.

785 Binley A, Henry-Poulter S, and Shaw B. Examination of solute transport in an 786 undisturbed soil column using electrical resistance tomography. Water Resour. $787 \quad$ Res. 1996; 32: 763-769.

788 Binley AM and Kemna A. DC resistivity and induced polarization methods. In: 789 Rubin Y, Hubbard SS, editors. Hydrogeophysics. Water Sci. Technol. Library, Ser. $790 \quad 50$, Springer, New York; 2005, p. 129-156.

791 Bohidar RN and Hermance JF. The GPR refraction method. Geophysics 2002; 67(5): $792 \quad 1474-1485$.

793 Brovelli A and Cassiani G. Effective permittivity of porous media: a critical analysis 794 of the complex refractive index model. Geophys. Prospect. 2008; 56(5): 715-727, 795 doi: $10.1111 / \mathrm{j} .1365-2478.2008 .00724 . x$ 
796 Brovelli A and Cassiani G. Combined estimation of effective electrical conductivity 797 and permittivity for soil monitoring. Water. Resour. Res. 2011; 47(8): W08510, 798 doi:10.1029/2011WR010487

799 Busch S, van der Kruk J, Bikowski J, and Vereecken H Quantitative conductivity and 800 permittivity estimation using full-waveform inversion of on-ground GPR data. 801 Geophysics 2012; 77(6): H79-H91, doi: 10.1190/GEO2012-0045.1

802 Busch S, Weihermuller L, Huisman JA, Steelman CM, Endres LA, Vereecken H, and 803 van der Kruk J. Coupled hydrogeophysical inversion of time-lapse surface GPR 804 data to estimate hydraulic properties of a layered subsurface. Water. Resour. 805 Res. 2014; 49(12): 8480-8494, doi:10.1002/2013WR013992

806 Camporese M, Paniconi C, Putti M, and Orlandini S. Surface-subsurface flow 807 modeling with path-based runoff routing, boundary condition-based coupling, 808 and assimilation of multisource observation data. Water Resour. Res. 2010; 809 46(2): W02512, doi:10.1029/2008WR007536Camporese M., G. Cassiani, R. 810 Deiana and P. Salandin, 2011, Assessment of local hydraulic properties from 811 electrical resistivity tomography monitoring of a three-dimensional synthetic 812 tracer test experiment, Water Resources Research, 47, W12508, 813 doi:10.1029/2011WR010528, 2011.

814 Caputo MC, De Carlo L, and Masciale R. Hydrogeophysical approach to measure 815 hydraulic parameters on unsaturated rocks. Fresen. Environ. Bulletin 2012; $81621(10 \mathrm{~A}): 3077-3082$.

817 Cassiani G and Binley A Modeling unsaturated flow in a layered formation under 818 quasi-steady state conditions using geophysical data constraints. Adv. Water 819 Resour. 2005; 28(5): 467-477. 
820 Cassiani G, Binley AM, and Ferré TPA. Unsaturated zone processes. In: Vereecken

821 H et al. editors. Applied Hydrogeophysics, Springer-Verlag, Berlin; 2006; 71: p. $822 \quad 75-116$.

823 Cassiani G, Fusi N, Susanni D, and Deiana R. Vertical radar profiling for the 824 assessment of landfill capping effectiveness. Near Surf. Geophys. 2008; 6(2): 825 133-142, doi: 10.3997/1873-0604.2008010

826 Cassiani G, Godio A, Stocco S, Villa A, Deiana R, Frattini P, and Rossi M. Monitoring 827 the hydrologic behaviour of a mountain slope via time-lapse electrical 828 resistivity tomography. Near Surf. Geophys. 2009a; 7(5-6): 475-486.

829 Cassiani G, Giustiniani M, Ferraris S, Deiana R, and Strobbia C, Time-lapse surface830 to-surface GPR measurements to monitor a controlled infiltration experiment. 831 B. Geofis. Teor. Appl. 2009b; 50(2): 209-226.

832 Cassiani G, Kemna A, Villa A, and Zimmermann E. 2009c. Spectral induced 833 polarization for the characterization of free-phase hydrocarbon contamination 834 of sediments with low clay content. Near Surf. Geophys. 2009c; 7(5-6): 547-562, 835 doi:10.3997/1873-0604.2009028

836 Cassiani G, Ursino N, Deiana R, Vignoli G, Boaga J, Rossi M, Perri MT, Blaschek M, 837 Duttmann R, Meyer S, Ludwig R, Soddu A, Dietrich P, and Werban U. Non838 invasive monitoring of soil static characteristics and dynamic states: a case 839 study highlighting vegetation effects. Vadose Zone J. 2012; 11(3), doi: $840 \quad 10.2136 / 2011.0195$

841 Clément R, Descloitres M, Günther T, Ribolzi O, and Legchenko A. Influence of 842 shallow infiltration on time-lapse ERT: Experience of advanced interpretation. 843 C. R. Geosci. 2009; 341(10-11): 886-898, doi: 10.1016/j.crte.2009.07.00 
844 Daily W, Ramirez A, LaBrecque D, and Nitao J. 1 Electrical resistivity tomography of 845 vadose water movement. Water Resour. Res. 1992; 28(5): 1429-1442.

846 Day-Lewis FD, Singha K, and Binley AM. Applying petrophysical models to radar 847 travel time and electrical resistivity tomograms: Resolution-dependent 848 limitations. J. Geophys Res.-Sol. Ea. 2005; 110(B8): B08206.

849 Ferré TPA, Bentley L, Binley A, Linde N, Kemna A, Singha K, Holliger K, Huisman S, 850 and Minsley B. Critical steps for the continuing advancement of 851 hydrogeophysics. EOS T. Am. Geophys. Un. 2009; 90(23): 200.

852 Fisher E, McMechan GA, and Annan AP. Acquisition and processing of wide853 aperture ground-penetrating radar data. Geophysics 1992; 57(3): 495-504.

854 Gelagedara LW, Parkin GW, Redman JD, von Bertoldi P, and Endres AL. Field 855 studies of the GPR ground wave method for estimating soil water content 856 during irrigation and drainage. J. Hydrol. 2005; 301(1-4): 182-197, doi: $857 \quad$ 10.1016/j.jhydrol.2004.06.031

858 Gerlitz K, Knoll MD, Cross GM, Luzitano RD, and Knight R. Processing ground 859 penetrating radar data to improve resolution of the near-surface targets. In: 860 Proceedings of the Symposium on the Application of Geophysics to Engineering 861 and Environmental Problems; 1993: 561-575

862 Greaves RJ, Lesmes DP, Lee JM, and Toksoz MN. Velocity variations and water 863 content estimated from multi-offset ground-penetrating radar. Geophysics 864 1996; 61(3): 683-695, doi: 10.1190/1.1443996

865 Hinnell AC, Ferré TPA, Vrugt JA, Huisman JA, Moysey S, Rings J, and Kowalsky MB. 866 Improved extraction of hydrologic information from geophysical data through 
867

868

869

870

871

872

873

874

875

876

877

878

879

880

881

882

883

884

885

886

887

888

889

890

coupled hydrogeophysical inversion. Water Resour. Res. 2010; 46(4): W00D40, doi: 10.1029/2008WR007060

Hubbard SS, Grote K, and Rubin Y. Mapping the volumetric soil water content of a California vineyard using high-frequency GPR ground wave data. The Leading Edge 2002; 21: 552-559.

Huisman JA, Sperl C, Bouten W, and Verstraten JM. Soil water content measurements at different scales: accuracy of time domain reflectometry and ground-penetrating radar. J. Hydrol. 2001; 245(1-4), 48-58.

Huisman JA, Hubbard SS, Redman JD, and Annan AP. Measuring soil water content with ground penetrating radar: a review. Vadose Zone J. 2003; 2(4): 477-491.

Klotzsche A, van der Kruk J, Meles G, and Vereecken H. Crosshole GPR fullwaveform inversion of waveguides acting as preferential flow paths within aquifer systems. Geophysics 2012; 77(4): H57-H62.

Klotzsche A, van der Kruk J, Linde N, Doetsch J, and Vereecken H. 3-D characterization of high-permeability zones in a gravel aquifer using 2-D crosshole GPR full-waveform inversion and waveguide detection. Geophys. J. Int. 2013; $195(2): 932-944$.

La Brecque DJ, Heath G, Sharpe R, and Versteeg R. Autonomous monitoring of fluid movement using 3-D electrical resistivity tomography. J. Environ. Eng. Geoph. $2004 ; 9(3): 167-176$.

Lai W.L., S.C. Kou and C.S. Poon, 2012 Unsaturated zone characterization in soil through transient wetting and drying using GPR joint time-frequency analysis and grayscale images. J. Hydrol. 2012; 452-453: 1-13, doi: 10.1016/j.jhydrol.2012.03.044 
891 Lambot S, Slob EC, van den Bosch I, Stockbroeckx B, and Vanclooster M. Modeling 892 of ground-penetrating radar for accurate characterization of subsurface electric 893 properties. IEEE T. Geosci. Remote, 2004; 42(11): 2555-2568.

894 Linde N, Binley A, Tryggvason A, Pedersen L, and Revil A. Improved 895 hydrogeophysical characterization using joint inversion of cross-hole electrical 896 resistance and ground-penetrating radar traveltime data. Water Resour. Res. 897 2006; 42(12): W04410, doi:10.1029/2004WR003806

898 Manoli G., M. Rossi, D. Pasetto, R. Deiana, S. Ferraris, G. Cassiani and M. Putti, 2015, 899 An iterative particle filter approach for coupled hydro-geophysical modeling 900 and inversion of a controlled infiltration experiment, Journal of Computational 901 Physics, pp 37-51, doi: 10.1016/j.jcp.2014.11.035Mangel AR, Moysey SMJ, Ryan 902 JC, and Tarbutton JA. Multi-offset ground-penetrating radar imaging of a lab903 scale infiltration test. Hydrol. Earth Syst. Sc. 2012; 16: 4009-4022, doi: $904 \quad 10.5194 /$ hess-16-4009-2012.

905 McLaughlin D. An integrated approach to hydrologic data assimilation: 906 interpolation, smoothing, and filtering. Water Res. Resour. 2002; 25(8-12): $907 \quad 1275-1286$.

908 Menke W. Geophysical Data Analysis: Discrete Inverse Theory. Elsevier, New York; $909>1984$.

910 Michot D, Benderitter Y, Dorigny A, Nicoullaud B, King D, and Tabbagh A. Spatial 911 and temporal monitoring of soil water content with an irrigated corn crop 912 cover using surface electrical resistivity tomography. Water Res. Resear., 2003; 913 39(5): 1138. doi:10.1029/2002WR001581.

914 Moradkhani H, Hsu K-L, Gupta H, and Sorooshian S. Uncertain assessment of 
915 hydrologic model states and parameters: Sequential data assimilation using the 916 particle filter. Water Res. Resear. 2005; 41(5), doi: 10.1029/2004WR003604

917 Moysey SMJ. Hydrologic trajectories in transient ground-penetrating radar 918 reflection data. Geophysics, 2010; 75(4): WA211-WA219, doi: 10.1190/1$919 \quad 3463416$

920 Nash JE and Sutcliffe JV. River flow forecasting through conceptual models part I 921 A discussion of principles. J. Hydrol. 1970; 10(3): 282-290.

922 Perri MT, Cassiani G, Gervasio I, Deiana R, Binley AM. A saline tracer test 923 monitored via both surface and cross-borehole electrical resistivity 924 tomography: Comparison of time-lapse result., J. App. Geophys. 2012; 79: 6-16, 925 doi:10.1016/j.jappgeo.2011.12.011

926 Rings J, Huisman JA, and Vereecken H, 2010. Coupled hydrogeophysical parameter 927 estimation using a sequential Bayesian approach. Hydrol. Earth Syst. Sc. 2010; $928 \quad 14: 545-556$.

929 Rossi M, Cassiani G, and Binley A. A stochastic analysis of cross-hole gpr zero-offset 930 profiles for subsurface characterization. Vadose Zone J. 2012; 11(4), doi: $931 \quad 10.2136 /$ vzj2011.0078

932 Roth K, Schulin R, Fluhler H, and Hattinger W. Calibration of time domain 933 reflectometry for water content measurements using a composite dielectric 934 approach. Water Resour. Res. 1990; 26(10): 2267-2273.

935 Rucker DF and Ferré TPA. Correcting water content measurement errors 936 associated with critically refracted first arrivals on zero offset profiling borehole 937 ground penetrating radar profiles. Vadose Zone J. 2004a; 3(1): 278-287.

938 Rucker DF and Ferré TPA. Parameter estimation for soil hydraulic properties using 
939

940

941

942

943

944

945

946

947

948

949

950

951

952

953

954

955

956

957

958

959

960

961

962

zero-offset borehole radar. Soil Sci. Soc. Am. J. 2004b; 68(5): 1560-1567.

Schmelzbach C, Tronicke J, and Dietrich P. High-resolution water content estimation from surface-based ground-penetrating radar reflection data by impedance inversion. Water Resour. Res. 2012; 48(8): W08505, doi:10.1029/2012WR011955

Singha K and Gorelick SM. Saline tracer visualized with three-dimensional electrical resistivity tomography: Field-scale spatial moment analysis. Water Resour. Resear. 2005; 41(5), W05023, doi:10.1029/2004WR003460

Slater L, Binley AM, Daily W, and Johnson R. Cross-hole electrical imaging of a controlled saline tracer injection. J. App. Geophys. 2000; 44(2-3): 85-102.

Steelman CM, Endres AL, and Jones JP., 2012,High-resolution ground-penetrating radar monitoring of soil moisture dynamics: Field results, interpretation, and comparison with unsaturated flow model. Water Resour. Res. 2012; 48(9): W09538, doi: 10.1029/2011WR011414

Strobbia C and Cassiani G. Multi-layer GPR guided waves in shallow soil layers for the estimation of soil water content. Geophysics 2007; 72(4): J17-J29, doi: $10.1190 / 1.2716374$

Topp GC, Davis JL, and Annan AP. Electromagnetic determination of soil water content: measurements in coaxial transmission lines. Water Resour. Res. 1980; 16(3): 574-582.

Tran A.P, „M. Vanclooster, M.Zupanski, and S. Lambot, 2014, Joint estimation of soil moisture profile and hydraulic parameters by ground-penetrating radar data assimilation with maximum likelihood ensemble filter. Water Resour. Res. 2014; 50(4): 3131-3146, doi: 10.1002/2013WR014583 
963 Travelletti J, Sailhac P, Malet J-P, Grandjean G, and Ponton J., 2012,Hydrological

964 response of weathered clay-shale slopes: water infiltration monitoring with

965 time-lapse electrical resistivity tomography. Hydrol. Process. 2012;, 26(14):

966 2106-2119, doi: 10.1002/hyp.7983

967 van der Kruk J, Streich R, and Green AG. Properties of surface waveguides derived

968 from separate and joint inversion of dispersive TE and TM GPR data. Geophysics

$9692006 ; 71(1):$ K19-K29.

970 van Genuchten MT and Nielsen DR. On describing and predicting the hydraulic

971 properties of unsaturated soils. Ann. Geophys. 1985; 3(5): 615-628.

972 van Overmeeren RA, ,Sariowan SV, and Gehrels JC. Ground penetrating radar for

973 determining volumetric soil water content: Results of comparative

974 measurements at two test sites. J. Hydrol. 1997;197(1-4): 316-338.

975 Vignoli G, Deiana R, and Cassiani G, Focused inversion of vertical radar profile 976 (VRP) traveltime data. Geophysics 2012; 77(1): H9-H18, doi:

$977 \quad 10.1190 /$ GE02011-0147.1 


\section{TABLES}

979

\begin{tabular}{|c|c|c|c|}
\hline $\begin{array}{c}\text { Irrigation } \\
\text { steps }\end{array}$ & $\begin{array}{c}\text { Irrigation start } \\
{[\mathrm{min}]}\end{array}$ & $\begin{array}{c}\text { Irrigation end } \\
{[\mathrm{min}]}\end{array}$ & $\begin{array}{c}\text { Cumulative water } \\
\text { volume }\left[\mathbf{m}^{3}\right]\end{array}$ \\
\hline 1 & 0 & 115 & 2.509 \\
\hline 2 & 146 & 233 & 4.127 \\
\hline 3 & 264 & 327 & 5.652 \\
\hline
\end{tabular}

980

981 Table 1. Time schedule and irrigated volumes for the infiltration experiment.

982 


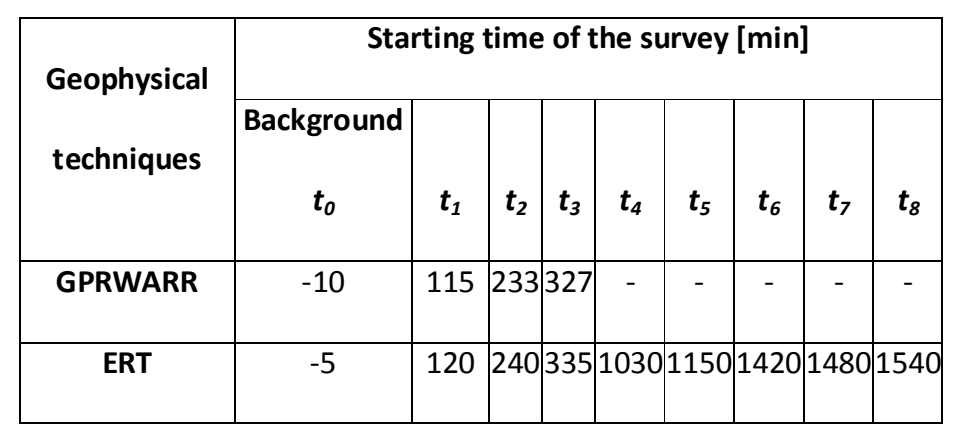

983

984 Table 2. Time schedule of the geophysical acquisitions; time is referred to the

985

irrigation start.

986 


\begin{tabular}{|c|c|c|c|c|c|c|}
\hline Time step & $\begin{array}{c}\text { Averaged } \\
\text { thickness } \\
{[\mathbf{m}]}\end{array}$ & $\begin{array}{c}\text { Standard } \\
\text { deviation of } \\
\text { thickness } \\
{[\mathbf{m}]}\end{array}$ & $\begin{array}{c}\text { Averaged } \\
\text { velocity } \\
{[\mathbf{m} / \mathbf{n s}]}\end{array}$ & $\begin{array}{c}\text { Standard } \\
\text { deviation of } \\
\text { velocity } \\
{[\mathbf{m} / \mathbf{n s}]}\end{array}$ & $\begin{array}{c}\text { Number of } \\
\text { averaged } \\
\text { simulations }\end{array}$ & $\begin{array}{c}\text { NSI range of } \\
\text { averaged } \\
\text { simulations }\end{array}$ \\
\hline $\boldsymbol{t}_{\mathbf{1}}$ & 0.46 & 0.031 & 0.091 & 0.0013 & 197 & $0.984-0.987$ \\
\hline $\boldsymbol{t}_{\mathbf{2}}$ & 0.49 & 0.019 & 0.074 & 0.0006 & 106 & $0.886-0.889$ \\
\hline $\boldsymbol{t}_{3}$ & 0.74 & 0.016 & 0.081 & 0.0007 & 83 & $0.987-0.990$ \\
\hline
\end{tabular}

987

988

Table 3. Statistics of the GPR slab waveguide simulations that best fit the

989 measured dispersion curves.

990 


\begin{tabular}{|l|l|l|l|l|}
\hline Time-step & $\begin{array}{l}t_{1} \\
(\mathrm{~m})\end{array}$ & $\begin{array}{l}t_{2} \\
(\mathrm{~m})\end{array}$ & $\begin{array}{l}t_{3} \\
(\mathrm{~m})\end{array}$ & $\begin{array}{l}\text { Mean Error } \\
(\mathrm{m})\end{array}$ \\
\hline GPR inversion & -0.46 & -0.49 & -0.74 & \\
\hline Posterior ERT & -0.32 & -0.52 & -0.66 & 0.083 \\
\hline Posterior GPR & -0.38 & -0.61 & -0.79 & 0.083 \\
\hline Posterior ERT-GPR & -0.34 & -0.54 & -0.70 & 0.070 \\
\hline
\end{tabular}

991

992

993

994

995 996

Table 4. Infiltration front depth for the first three time-steps, obtained from GPREM-waveguide inversion and from posterior hydrological forward models. The last 94 column is the average absolute error between the waterfront positions measured 95 with the GPR and those estimated with the posterior hydrological forward models. 
998

999

\begin{tabular}{|c|c|c|c|c|c|c|c|c|c|}
\hline \multicolumn{2}{|c|}{ Prior distribution } & \multicolumn{6}{c|}{ Posterior distribution } \\
\hline \multicolumn{2}{|c|}{} & \multicolumn{2}{|c|}{ ERT } & \multicolumn{2}{c|}{ GPR } & \multicolumn{2}{c|}{ ERT+GPR } & \multicolumn{2}{c|}{ GPR+ERT } \\
\hline Mean & St. dev. & Mean & St. dev. & Mean & St. dev. & Mean & St. dev. & Mean & St. dev. \\
\hline $\mathrm{m} / \mathrm{s}$ & $\mathrm{m} / \mathrm{s}$ & $10^{-5} \mathrm{~m} / \mathrm{s}$ & $10^{-5} \mathrm{~m} / \mathrm{s}$ & $10^{-5} \mathrm{~m} / \mathrm{s}$ & $10^{-5} \mathrm{~m} / \mathrm{s}$ & $10^{-5} \mathrm{~m} / \mathrm{s}$ & $10^{-5} \mathrm{~m} / \mathrm{s}$ & $10^{-5} \mathrm{~m} / \mathrm{s}$ & $10^{-5} \mathrm{~m} / \mathrm{s}$ \\
\hline $1 \times 10^{-1}$ & $1 \times 10^{-1}$ & 0.99 & 0.014 & 2.50 & 0.148 & 1.15 & 0.014 & 1.11 & 0.015 \\
\hline $1 \times 10^{-5}$ & $1 \times 10^{-5}$ & 1.02 & 0.008 & 2.63 & 0.083 & 1.14 & 0.076 & 1.08 & 0.018 \\
\hline $1 \times 10^{-3}$ & $1 \times 10^{-3}$ & 0.90 & 0.018 & 2.86 & 0.053 & 1.17 & 0.032 & 1.06 & 0.012 \\
\hline
\end{tabular}

1000

1001

Table 5: Prior and posterior distributions of the hydraulic conductivity $\mathbf{K}_{\mathrm{s}}$ for the

1002 different data assimilation schemes

1003

1004 


\begin{tabular}{|l|l|l|l|l|l|l|l|l|l|}
\hline Time-step & $t_{1}$ & $t_{2}$ & $t_{3}$ & $t_{4}$ & $t_{5}$ & $t_{6}$ & $t_{7}$ & $t_{8}$ & Mean \\
\hline Posterior ERT & 3.5 & 4.3 & 3.7 & 3.1 & 3.1 & 3.4 & 3.5 & 3.6 & 3.525 \\
\hline Posterior GPR & 3.6 & 4.4 & 3.7 & 4.4 & 4.5 & 5.1 & 5.3 & 5.4 & 4.550 \\
\hline $\begin{array}{l}\text { Posterior ERT- } \\
\text { GPR }\end{array}$ & 3.5 & 4.2 & 3.6 & 3.2 & 3.2 & 3.6 & 3.7 & 3.8 & 3.600 \\
\hline
\end{tabular}

1007

1008

Table 6. Root mean square relative error between the field measured electric 1009 resistance value sand those simulated with the posterior hydrological forward 1010 models (results in \%). The last column is the mean in time of these errors. The 1011 relative error is adopted because the electric resistances vary over several orders of 1012 magnitude.

1013 


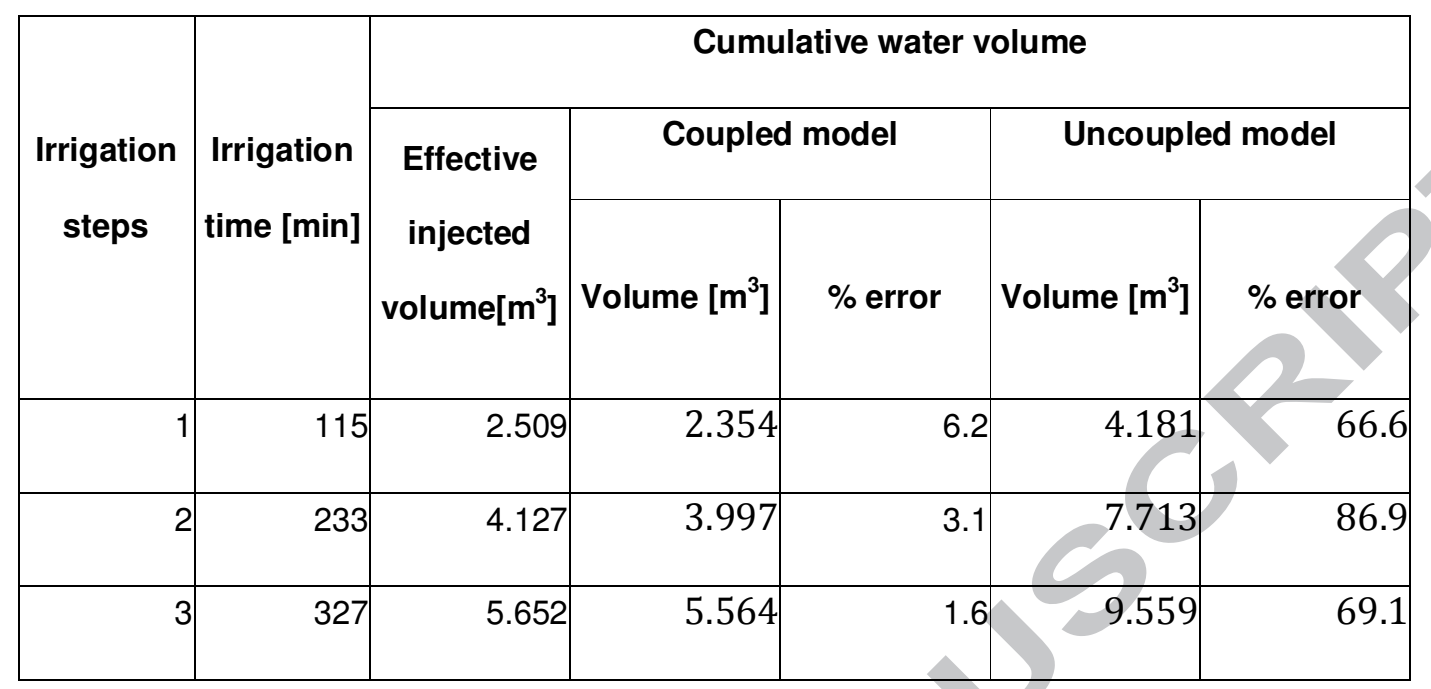

1016

Table 7. Mass balance achieved with coupled and uncoupled hydro-geophysical

1017 inversions. 


\section{FIGURES}

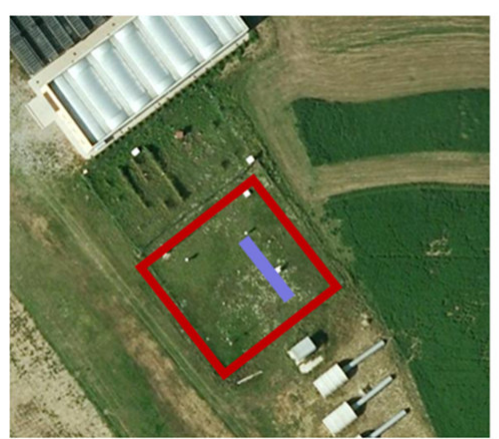

(a)

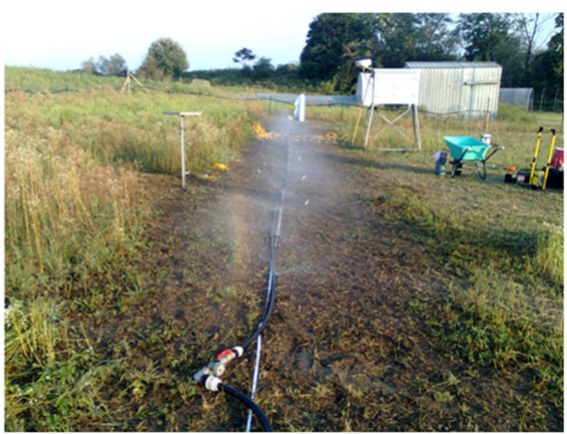

(b)

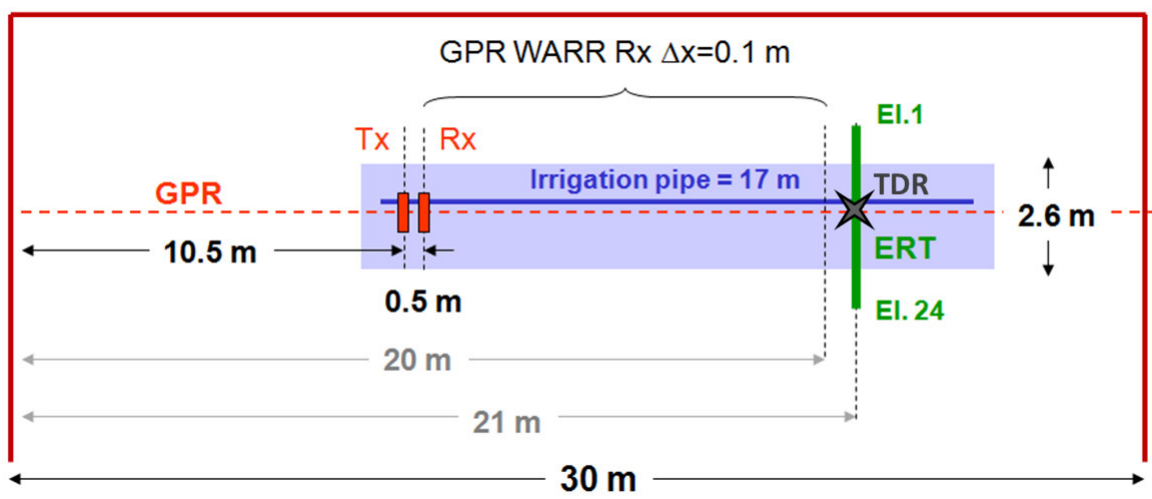

(c)

1022 Figure 1. Scheme and location of the experiment: (a) aerial view of the field with the 1023 irrigated zone highlighted in blue; (b) the sprinkler line during the irrigation; (c) 1024 scheme of the geophysical surveys and position of the irrigated soil. 


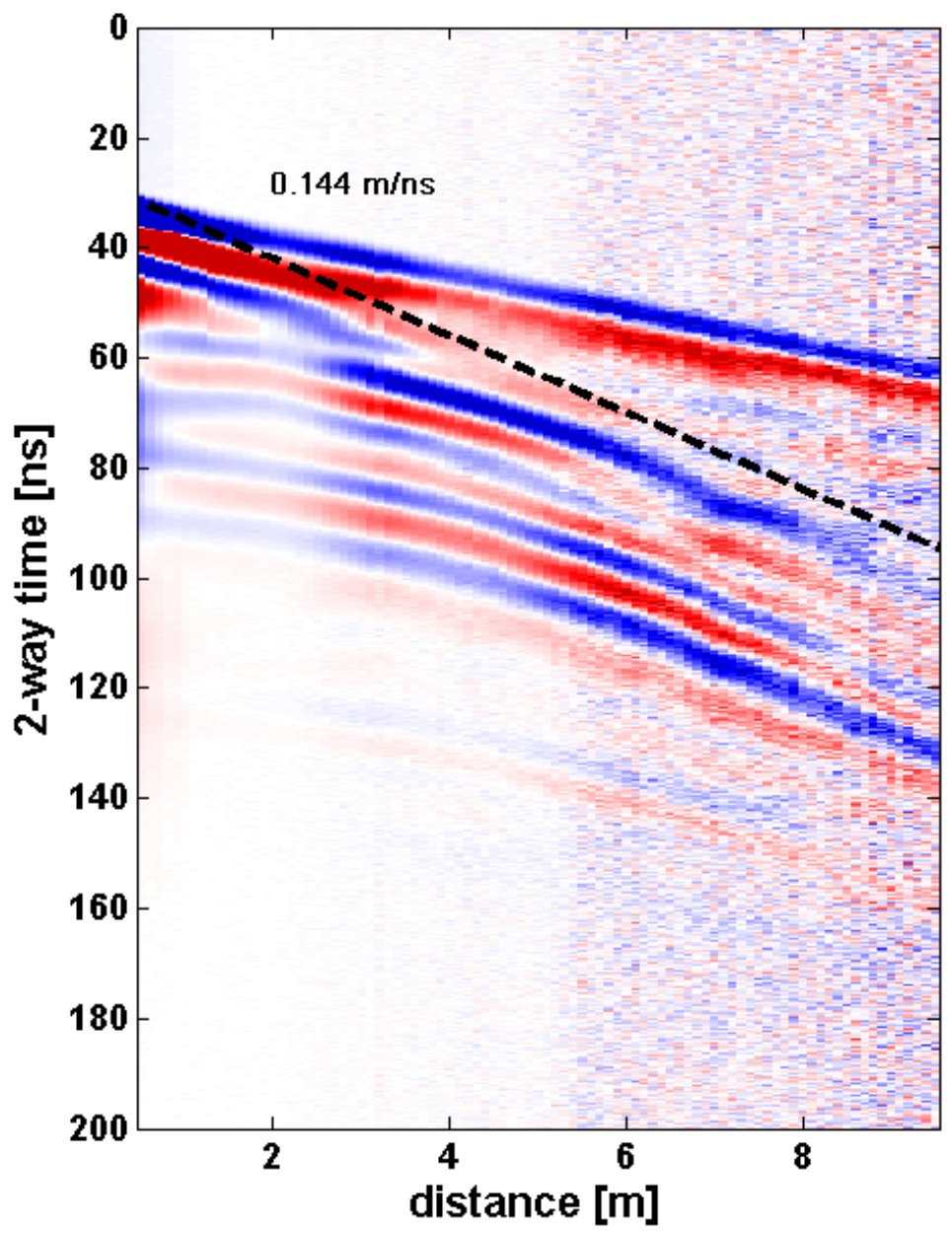

1026

1027

1028 Figure 2. Background WARR survey with the identification of the direct wave 1029 through the ground.

1030 

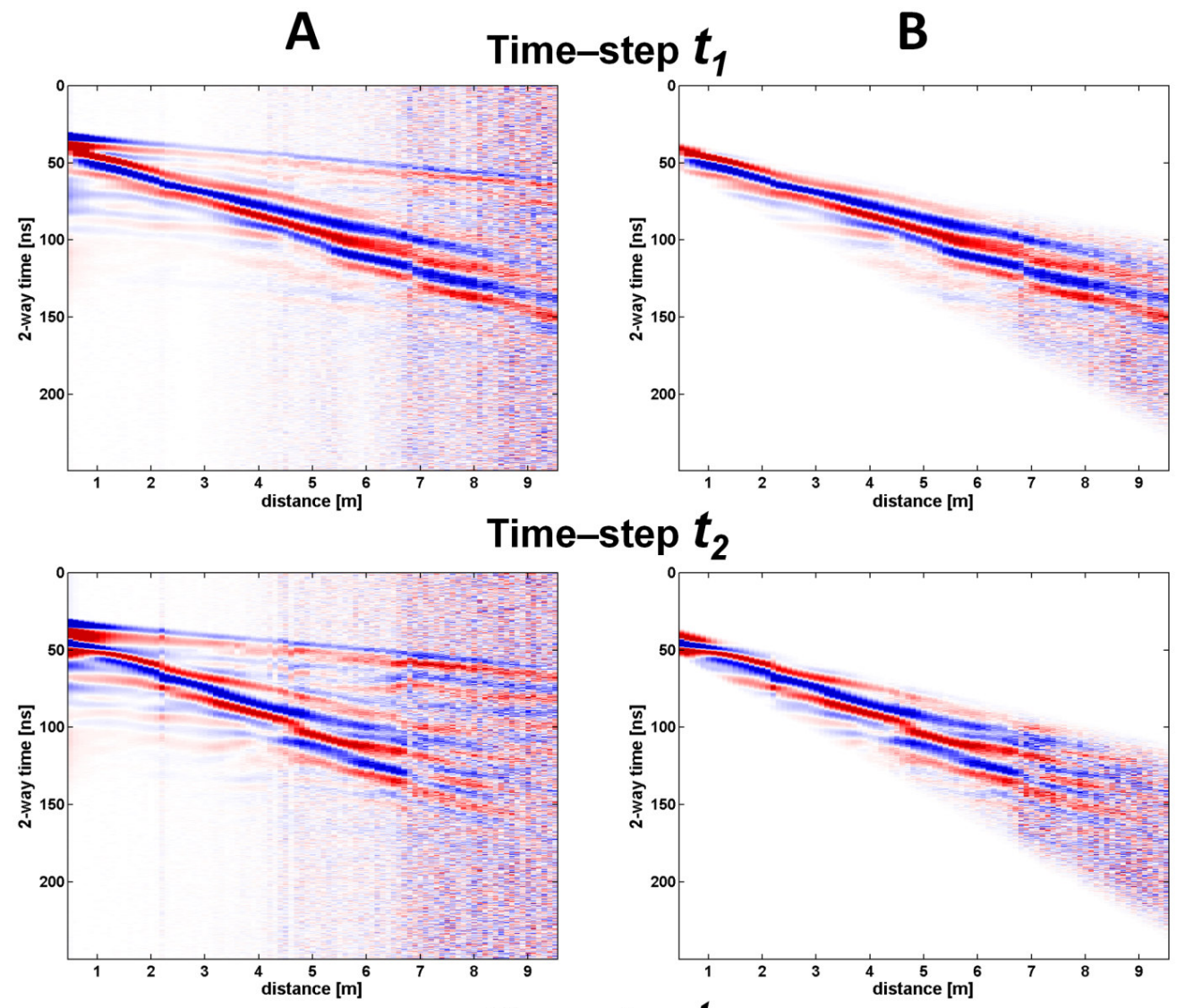

Time-step $\boldsymbol{t}_{3}$
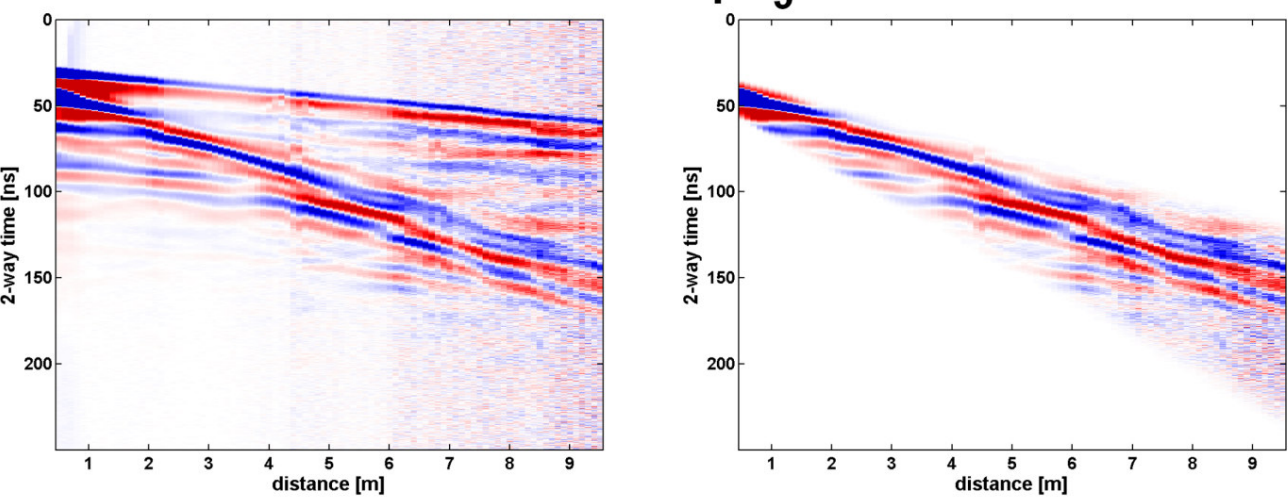

1032

1033 Figure 3. Field measured WARR radargrams at the times $t_{1}, t_{2}$ and $t_{3}$. A) On the left, 1034 the radargrams are filtered only by the "dewow" procedure (traces are normalized). 1035 B) On the right, the same radargrams are displayed after the preprocessing (muting 1036 and FIR filter). 

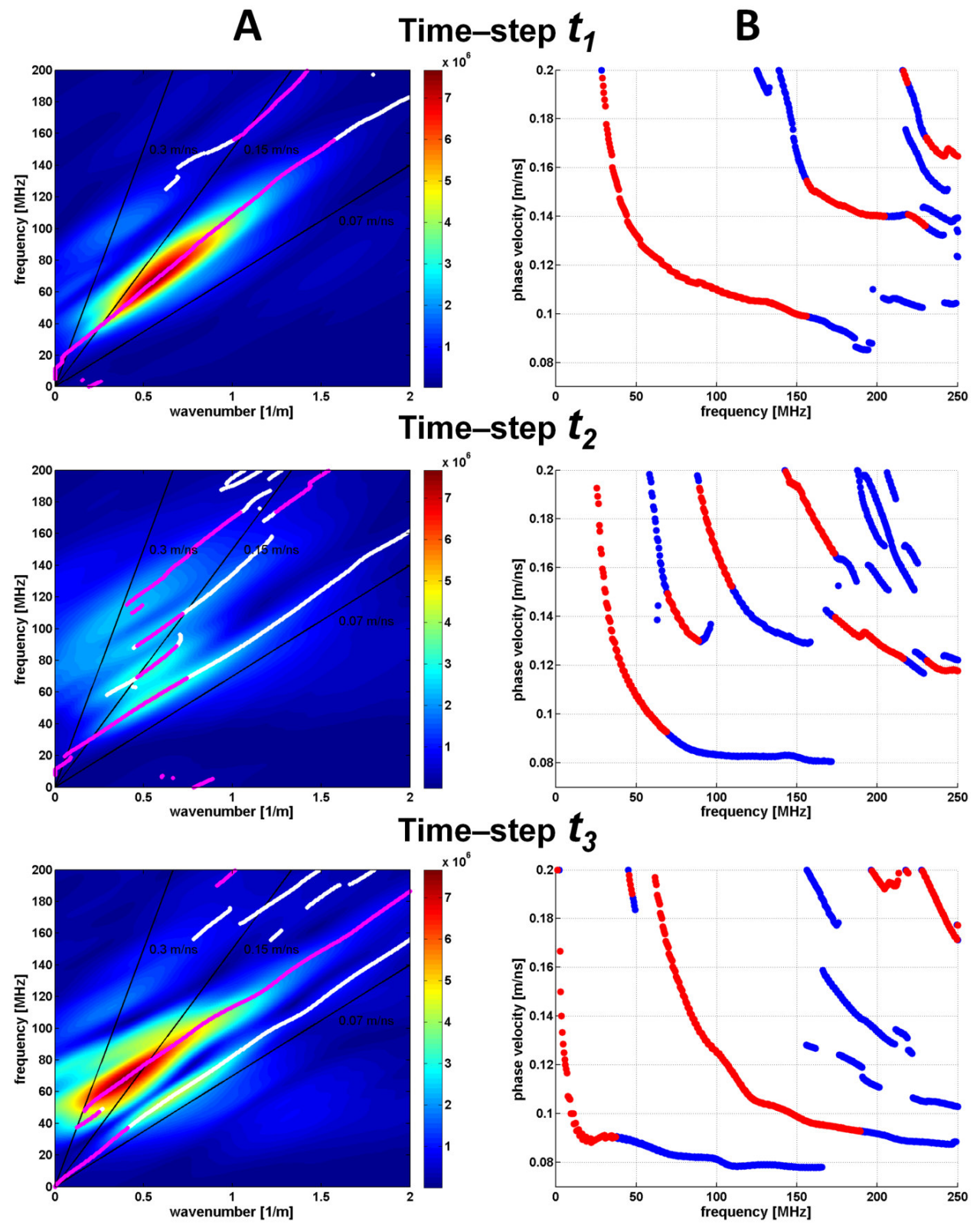

1038 Figure 4. Analysis of the GPR soundings in the frequency domain. (a) On the left, the 1039 f-kdomain are displayed with the superimposition of the maxima of the spectral 1040 density (magenta dots for main maxima, white dots for local maxima). Power 1041 spectrum density scale in $\mathrm{V}^{2} / \mathrm{Hz}$. (b) On the right, the dispersion curves inferred from 1042 f-k maxima: red and blue dots correspond to absolute and local maxima, respectively. 

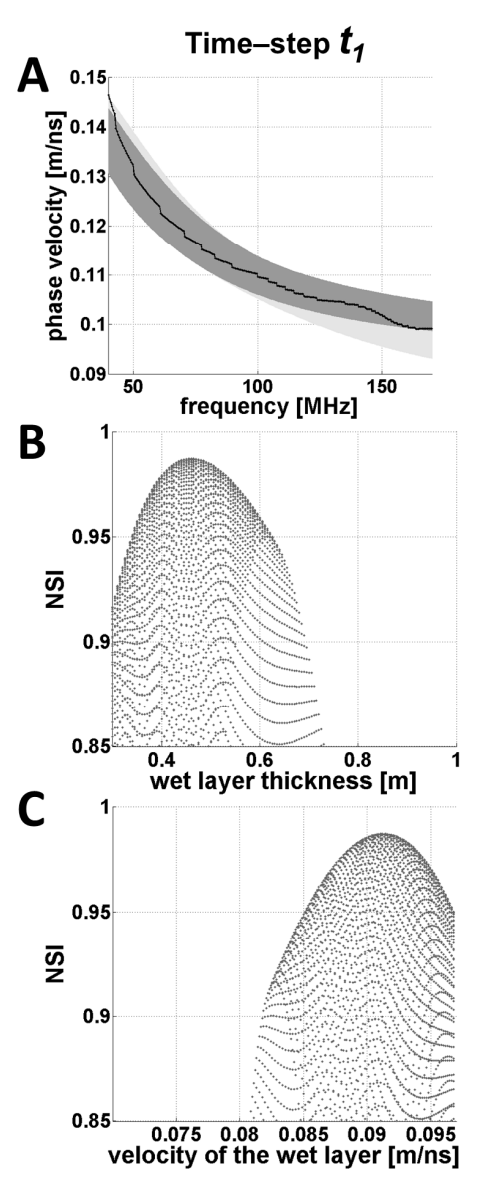
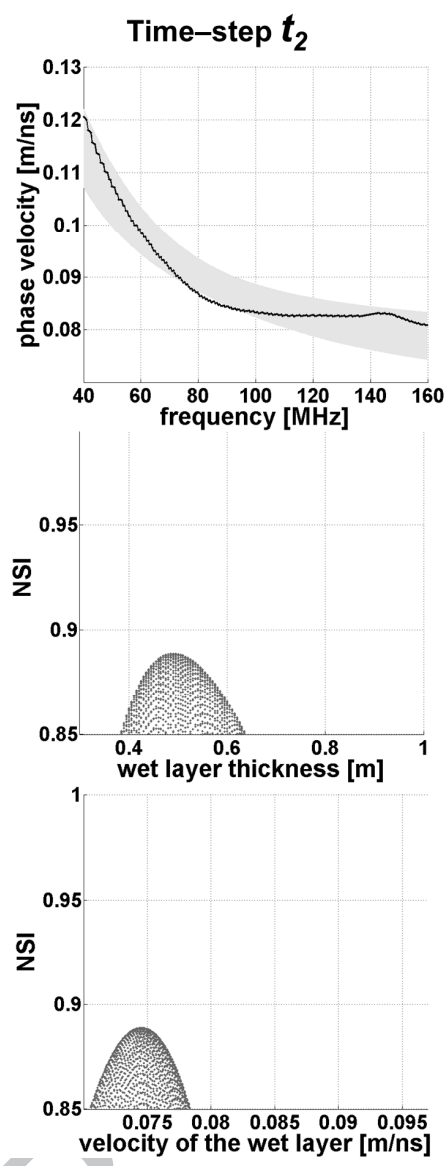
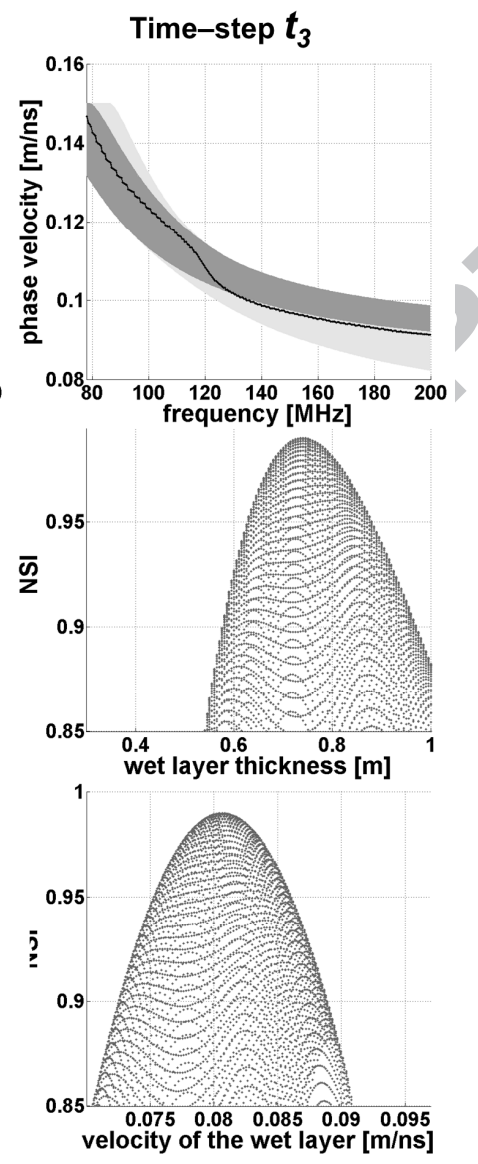

Figure 5. Parameterizations of the simulations of slab waveguides that best fit the measured dispersion curves. (a) Superposition of the field-derived dispersion curves 1048 (black dotted lines)and of the best simulated dispersion curves: light gray lines with $10490.85<N S I>0.95$ and dark gray lines with NSI>0.95. (b) Wet layer thickness from the 1050 best simulations plotted against NSI>0.85. (c) Wet layer velocity from the best 1051 simulations plotted against NSI>0.85. 
1053

1054

1055

1056

1057

1058

1059

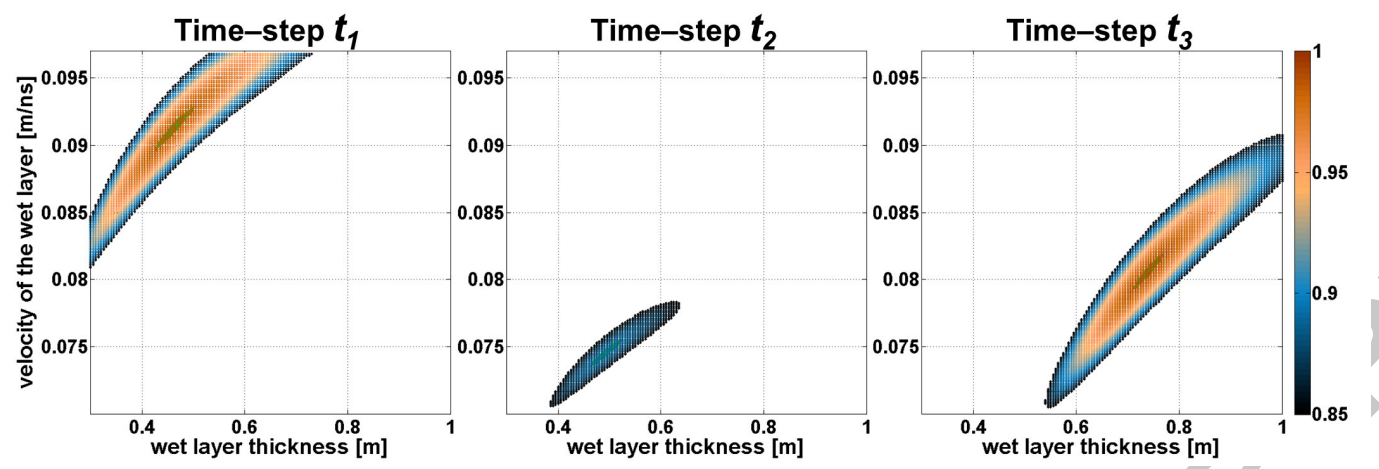

Figure 6. Correlation between the simulated parameters: velocity and thickness of the layer that guides EM waves; color bar is NSI value. Green polygon highlights the simulations with highest NSI values for each time-steps: NSI>0.984 for $t_{1}, N S I>0.886$ for $t_{2}, N S I>0.987$ for $t_{3}$. 
A

B
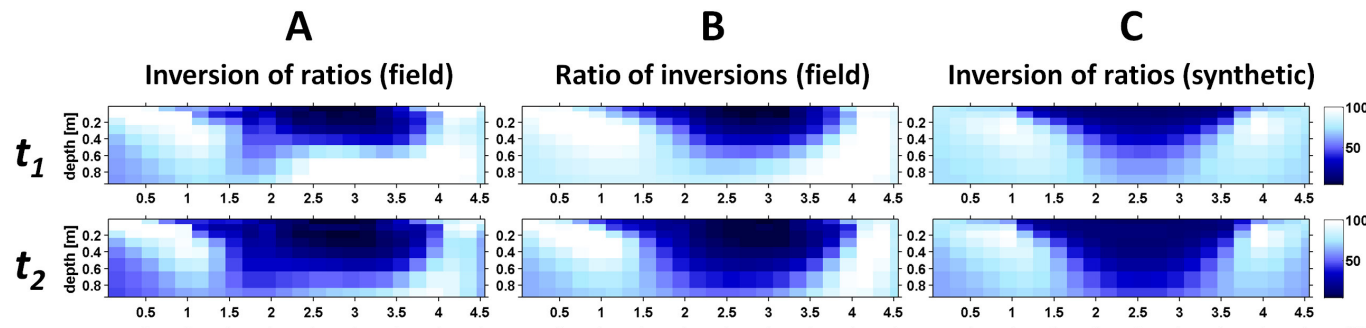

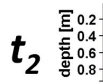

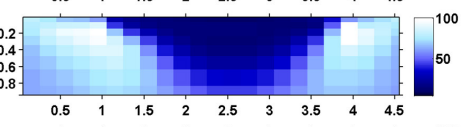

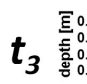
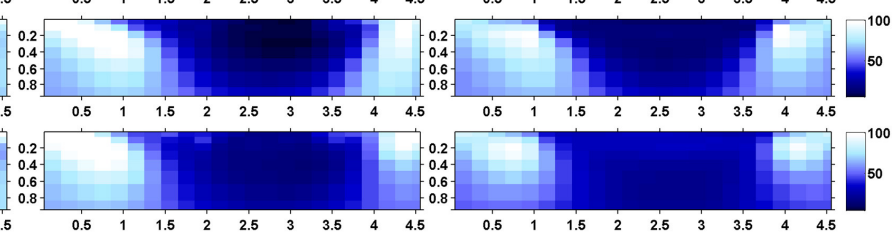

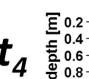

$\begin{array}{lllllllll}0.5 & 1 & 1.5 & 2 & 2.5 & 3 & 3.5 & 4 & 4.5\end{array}$
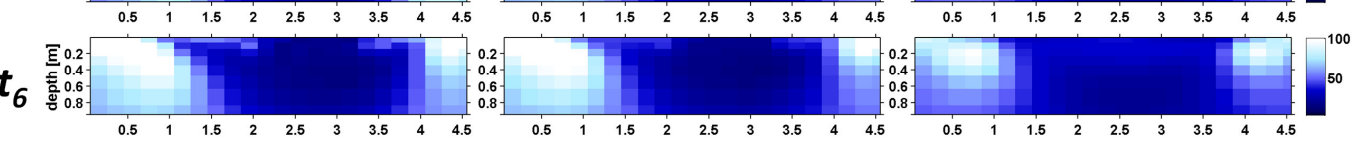

1060
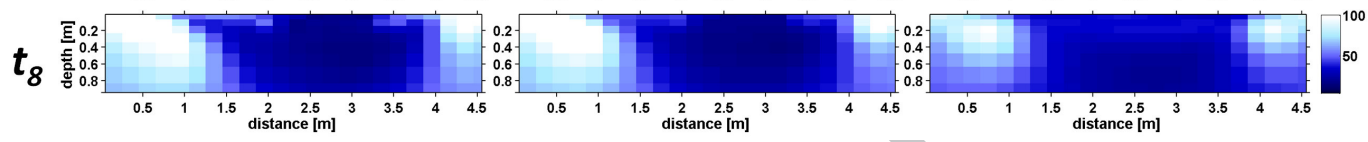

1061 Figure 7. Time-lapse of inverted electrical resistivity profiles displayed as percentage 1062 of variation respect to background. A) Inversion of the ratio of apparent resistivities, 1063 measured at the field, respect to background survey. B) Ratio of the inverted profiles 1064 related to background inversion. C) Inversion of the ratio of synthetic apparent 1065 resistivities, simulated through the hydrological model, respect to the assumed homogeneous background state. 
1070

1071

1072

1073

1074

1075

1076

1077

1078

1079

1080
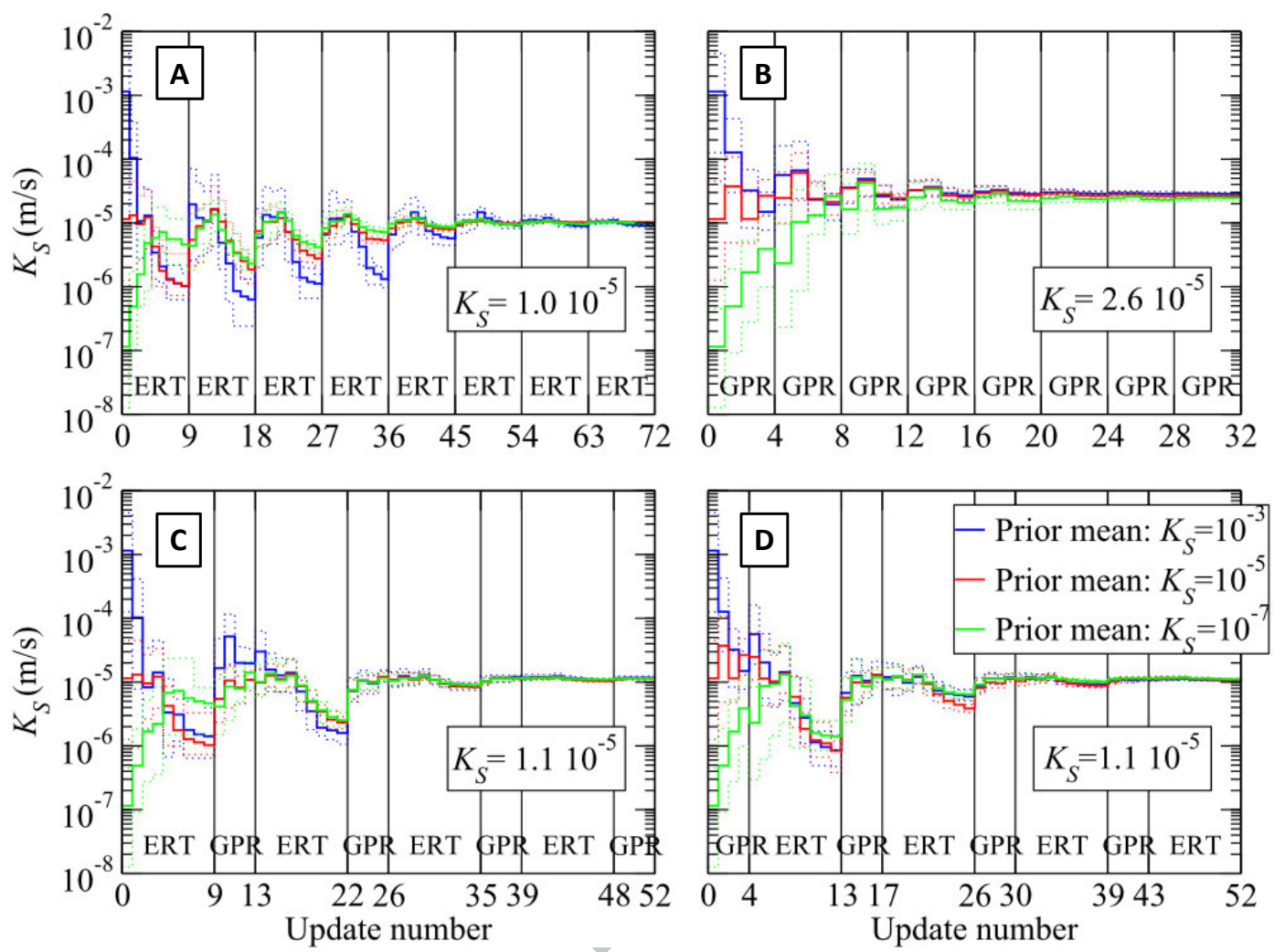

Figure 8. $\boldsymbol{K}_{\boldsymbol{s}}$-distributionduring the iteration of the data assimilation framework. The lines of different colors (blue, red and green) point out different initial distribution of the parameter: solid line is the mean of the distribution, dashed lines are the maximum and minimum vales in the range. (a) sequential assimilation of the ERT data. (b) sequential assimilation of the waterfront position from GPR data. (c) sequential assimilation of ERT and GPR information. (d) sequential assimilation of GPR and ERT information. The vertical lines, including the graph extremes, indicate the 9 measurement instants ( $t_{0}$ to $t_{8}$ ). 

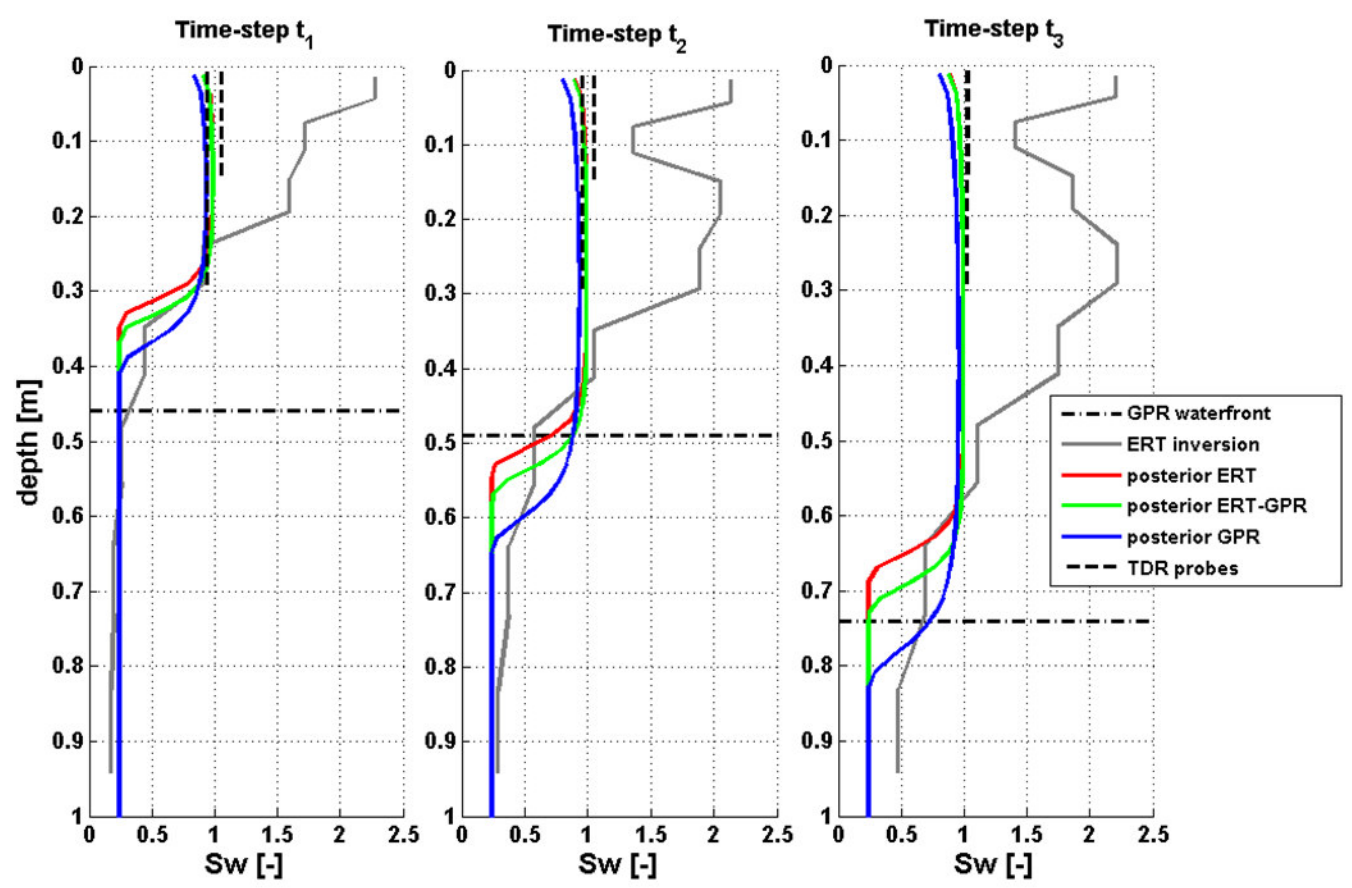

Figure 9. Vertical profiles of water saturation, extrapolated on the position of the sprinklers line. Solid lines of red, blue and green colors are the results of forward hydrological models obtained with the $\boldsymbol{K}_{\boldsymbol{s}}$ estimation assimilating only ERT, only GPR and both techniques, respectively. Gray solid line is the result of the uncoupled ERT inversion. The horizontal black dot-dashed line is the estimation of waterfront location from GPR-EM-waveguide inversion. The vertical black dashed lines are the estimated water saturation achieved by TDR probes (15 and $30 \mathrm{~cm}$ length). 


\section{Synthetic $\rho$ distribution $[\Omega \cdot m]$}
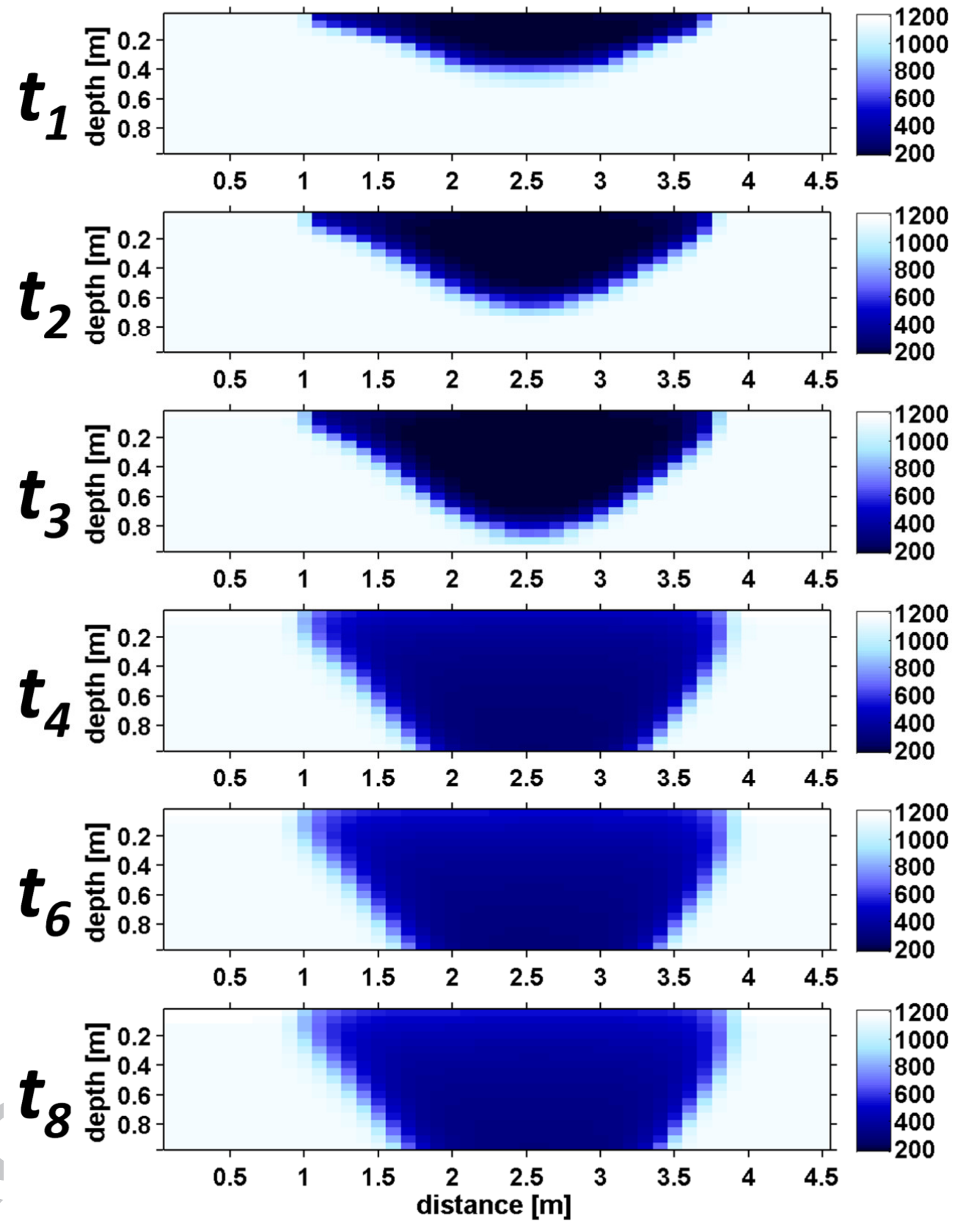

1092 distance $[\mathrm{m}]$

1093 Figure 10. Electrical resistivity sections at different time steps, derived by the 1094 hydrological model inferred from the assimilation of both ERT and GPR datasets. 